\title{
Design of Passivity-based Damping Controller for Suppressing Power Oscillations in DC Microgrids
}

\author{
Jeung, Yoon-Cheul; Lee, Dong Choon; Dragicevic, Tomislav; Blaabjerg, Frede
}

Published in:

IEEE Transactions on Power Electronics

Link to article, DOI:

10.1109/TPEL.2020.3024716

Publication date:

2020

Document Version

Peer reviewed version

Link back to DTU Orbit

Citation $(A P A)$ :

Jeung, Y-C., Lee, D. C., Dragicevic, T., \& Blaabjerg, F. (2020). Design of Passivity-based Damping Controller for Suppressing Power Oscillations in DC Microgrids. IEEE Transactions on Power Electronics, 36(4), 4016 - 4028. https://doi.org/10.1109/TPEL.2020.3024716

\section{General rights}

Copyright and moral rights for the publications made accessible in the public portal are retained by the authors and/or other copyright owners and it is a condition of accessing publications that users recognise and abide by the legal requirements associated with these rights.

- Users may download and print one copy of any publication from the public portal for the purpose of private study or research.

- You may not further distribute the material or use it for any profit-making activity or commercial gain

- You may freely distribute the URL identifying the publication in the public portal 


\title{
Design of Passivity-based Damping Controller for Suppressing Power Oscillations in DC Microgrids
}

\author{
Yoon-Cheul Jeung, Member, IEEE, Dong-Choon Lee, Senior Member, IEEE, Tomislav Dragicevic, Senior Member, \\ IEEE, and Frede Blaabjerg, Fellow, IEEE
}

\begin{abstract}
In this paper, a novel damping control scheme for $\mathrm{V} / \mathrm{I}$ droop-controlled DC microgrids is proposed to attenuate the oscillatory components in the power and current. At first, the model of the DC microgrid is introduced providing stability analysis. Then, the damping controller is designed using the interconnection and damping assignment - passivity-based control (IDA-PBC) methodology. In addition, the gain selection technique for the IDA-PBC is developed. The proposed control scheme ensures that the oscillations of the output power and current are effectively attenuated. The validity of the proposed control algorithm has been verified by the results from both hardware in-the-loop simulation (HILS) and proto-type experiments.
\end{abstract}

Index Terms - DC microgrids, damping control, IDA-PBC, V/I droop.

\section{INTRODUCTION}

In recent years, the direct current (DC) power systems have attracted a lot of attention in the areas of power transmission and distribution including ships, aircrafts, buildings, data centers and so on since they have advantages of no reactive power, fewer power conversion steps, and higher power density [1]-[4].

The DC microgrid can operate in a grid-connected mode or a stand-alone mode. The power sources are comprised of diesel engines, gas turbines, photovoltaic and wind power generation systems, fuel cells, and so on. Its power rating covers several $\mathrm{kW}$ or less to several hundreds of MW depending on the type of microgrids such as residential, educational, industrial and commercial applications [5]. A structure of the typical DC microgrid is shown in Fig. 1.

In spite of these advantages, the DC power system has some issues to solve technically, such as stability, accurate sharing of the output power and current, etc. In the past, various research have been conducted [2]. Among them, the suppression of power and current oscillations due to the droop control of

Manuscript received March 20, 2019; revised March 15, 2020 and July 24, 2020; accepted September 09, 2020. This work was supported by Korea Electric Power Corporation (Grant number: R18XA06-35). (Corresponding author: D.C. Lee.)

Y.-C. Jeung is with the Jeju Global Research center, Korea Institute of Energy Research, Daejeon 305-343, Korea (e-mail: ycjeung@kier.re.kr).

D.-C. Lee is with the Department of Electrical Engineering, Yeungnam University, Gyeongbuk 712-749, Korea (e-mail: dclee@yu.ac.kr).

T. Dragi "evic c is with the Center of Electric Power and Energy, Technical University of Denmark, 2800 Kgs. Lyngby, Denmark (e-mail: tomdr@elektro.dtu.dk).

F. Blaabjerg is with the Department of Energy Technology, Aalborg University, Aalborg 9220, Denmark (e-mail: fbl@et.aau.dk).

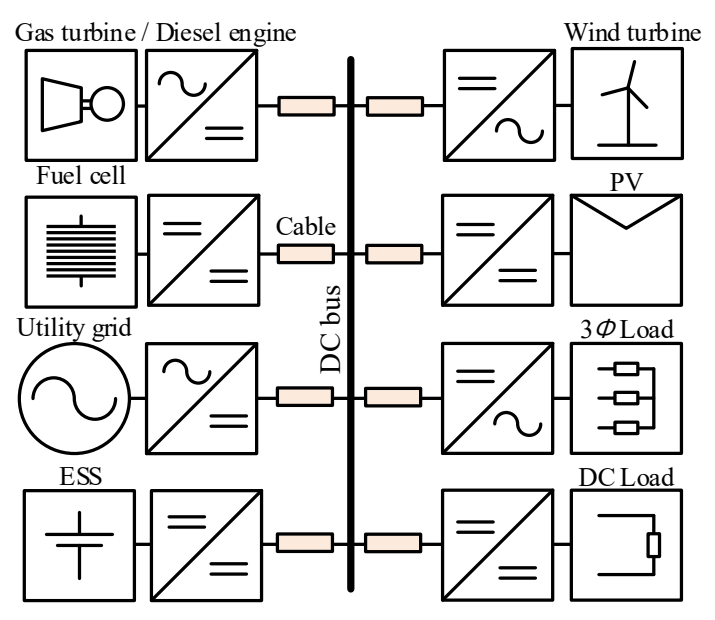

Fig. 1. Typical DC microgrid.

voltage-source converters (VSCs) has been studied a lot [6][12].

To attenuate the power and current oscillations, several damping control methods applied to the DC source side have been proposed [6]-[12]. At first, a low-pass filter (LPF) has been added in the droop control loop to achieve damping enhancement [6], [7]. In this method, the cut-off frequency of the LPF should be very low if the bandwidth (BW) of the voltage control loop is low. Also, the cut-off frequency of the LPF should be found appropriately for stable operation of the DC microgrid. In [8], a feed-forward control technique for the input voltage error has been proposed, which can be applied to the applications that include the variable DC sources. Furthermore, virtual impedance scheme has been proposed in [9], where the oscillatory components below the cut-off frequency of the feedback filter can be suppressed. In [10] and [11], the output current feedback scheme with an observer has been proposed, where the controller is relatively complex compared with other methods. Also, there are many controller gains which should be tuned at the different operating points. Meanwhile, in [12], a simple output current feedback control to compensate for the output of the voltage controller has been suggested with a proportional gain, which can suppress the oscillatory components effectively. However, there is a possibility that the behavior of the output of the DC source sensitively responds to the load disturbance since the output current is directly affected by the reference of the current controller where it usually requires the appropriate LPF. The 
conventional techniques aforementioned can suppress the oscillatory components effectively. However, the controller gains should be carefully tuned in order to achieve stable operation.

An energy-based controller design techniques have been utilized for the feedback control system to ensure asymptotic stability [13], [14]. The passivity-based control (PBC) is a type of energy-based control schemes. The passivity means that energy is only dissipated during the operation of the system. If a certain system is passive, it is known that it is always stable. The PBC design approach has been widely applied to the power system stabilization and power electronic converter control [15], [16]. Moreover, a passivity realization technique for DC microgrids with a voltage feed-forward control term has been introduced, which makes the overall system passive [14]. However, the conventional PBC design approach is very sensitive to load variations [17]. To overcome this issue, the interconnection and damping assignment PBC (IDA-PBC) has been proposed in [18], which is based on the mathematical model called a port-controlled Hamiltonian system (PCHS). In DC microgrids, the IDA-PBC has been applied to control buck [19], buck-boost [20], boost converters [21] and solid state transformers (SSTs) [22] to mitigate the effect of the constant power load (CPL). However, the information of power in the CPL is required in the control loop. In [23], the IDA-PBC has been applied to the controller design for the source-side dual active bridge (DAB) DC/DC converters in MVDC microgrids, where the controller is designed based on the mathematical model of the DAB converter. Recently, a DC-bus voltage and inner current control scheme for the ESS in DC microgrids has been proposed in [24], [25], which requires additional devices using communication lines for a damping of the voltage oscillations.

In this paper, a novel damping control scheme for V/I droopcontrolled microgrids is proposed, using the IDA-PBC theory. At first, the model of the DC microgrid is built, where the DC voltage source converter (VSC), CPL and resistive loads are included. Then, the effects of the system parameter change such as droop gains and control loop bandwidths on the bus impedance are investigated by using the passivity-based stability analysis. Next, the PCHS form of DC VSCs with new control inputs for damping is developed. Then, the proposed damping controller is designed with the IDA-PBC theory, for which a gain selection technique is developed. Finally, the validity of the proposed damping control scheme is verified by hardware-in-the-loop (HIL) simulation and experimental results.

\section{MODELING OF DC MICROGRIDS}

\section{A. DC microgrid}

Fig. 2. illustrates the circuit representation of a simplified DC microgrid. The DC source parts are modelled as DC/DC boost converters with ideal DC sources, of which the output terminal is connected to the DC bus through the line impedance. The
TABLE I

PARAMETERS OF DC MICROGRID

\begin{tabular}{|c|c|c|}
\hline & PARAMETERS & VALUES \\
\hline \multirow{10}{*}{$\begin{array}{c}\# 1 \& \# 2 \\
\text { DC VSC } \\
\text { (boost } \\
\text { converter) }\end{array}$} & Rated power & $5 \mathrm{~kW}$ \\
\hline & Input voltage & $310 \mathrm{~V}$ \\
\hline & Output capacitor $\left(C_{1}, C_{2}\right)$ & $1000 \mu \mathrm{F}$ \\
\hline & Switching / sampling freq. & $10 \mathrm{kHz} / 20 \mathrm{kHz}$ \\
\hline & Voltage control-loop BW $\left(f_{v c}\right)$ & $400 \mathrm{~Hz}$ \\
\hline & Current control-loop BW $\left(f_{c c}\right)$ & $2 \mathrm{kHz}$ \\
\hline & Droop controller gain $\left(r_{d}\right)$ & 2.88 \\
\hline & $\begin{array}{l}\text { Cut-off freq. of } \mathrm{LPF}_{\mathrm{d}} \text { for droop } \\
\text { control }\left(f_{d}\right)\end{array}$ & $40 \mathrm{~Hz}$ \\
\hline & $\begin{array}{l}\text { Cut-off freq. of } \operatorname{LPF}_{(\mathrm{v}, \mathrm{i})} \text { for voltage } \\
\text { and current control }\left(f_{v}, f_{i}\right)\end{array}$ & $1 \mathrm{kHz}, 5 \mathrm{kHz}$ \\
\hline & $\begin{array}{l}\text { Cut-off freq. of } \mathrm{HPF}_{(1-4)} \text { for } \\
\text { damping control }\left(f_{1} \text { to } f_{4}\right)\end{array}$ & $3 \mathrm{~Hz}$ \\
\hline \multirow{3}{*}{ DC bus } & DC-bus voltage $\left(v_{d c-b u s}\right)$ & $380 \mathrm{~V}$ \\
\hline & Line impedance $Z_{L I}\left(R_{L z l}, L_{L z l}\right)$ & $0.01 \Omega, 0.3 \mathrm{mH}$ \\
\hline & Line impedance $Z_{L 2}\left(R_{L z 2}, L_{L z 2}\right)$ & $0.02 \Omega, 0.6 \mathrm{mH}$ \\
\hline \multirow{2}{*}{ Load side } & $\begin{array}{c}\text { Rated load power } \\
(\mathrm{CPL}+\text { resistive load })\end{array}$ & $10 \mathrm{~kW}$ \\
\hline & Load capacitor $\left(C_{L 1}, C_{L 2}\right)$ & $1000 \mu \mathrm{F}$ \\
\hline
\end{tabular}

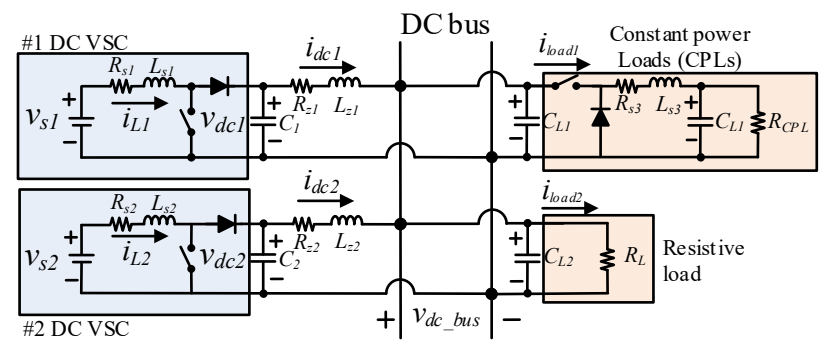

Fig. 2. Circuit representation of a simplified DC microgrid.

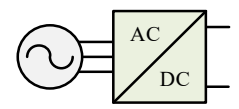

(a)

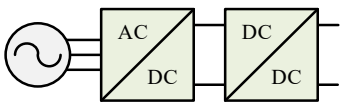

(b)

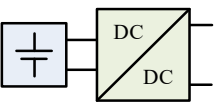

(c)
Fig. 3. Different types of DC output voltage converters. (a) AC/DC converter. (b) Rectifier and back-end DC/DC converter. (c) DC/DC converter.

load part consists of a CPL and a resistive load $\mathrm{R}_{\mathrm{L}}$. To represent the CPL characteristics, the buck converter is using a cascaded control structure for output voltage and inner current regulation. The capacitors $C_{L 1}$ and $C_{L 2}$ are connected to the DC bus in parallel. In Fig. 2, the meanings of symbols are as follows:

$-v_{s 1}$ and $v_{s 2}$ are the input voltages of VSCs,

$-v_{d c l}$ and $v_{d c 2}$ are the output voltages of VSCs,

- $C_{1}$ and $C_{2}$ are the output capacitors of VSCs,

- $R_{z 1}$ and $R_{z 2}$ are the line resistances,

- $L_{z 1}$ and $L_{z 2}$ are the line inductances,

- $v_{d c-b u s}$ is the DC-bus voltage,

- $C_{L 1}$ and $C_{L 2}$ are the input capacitors of the loads, 


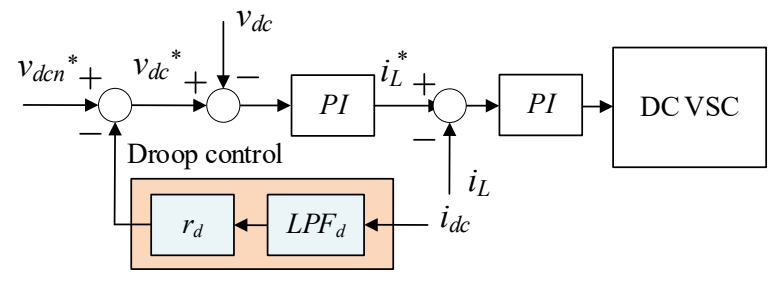

(a)

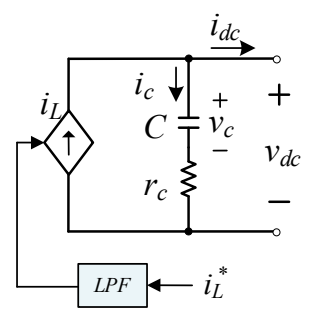

(b)

Fig. 4. DC voltage-source converter (a) Control block diagram of the DC-bus voltage. (b) Simplified equivalent circuit.

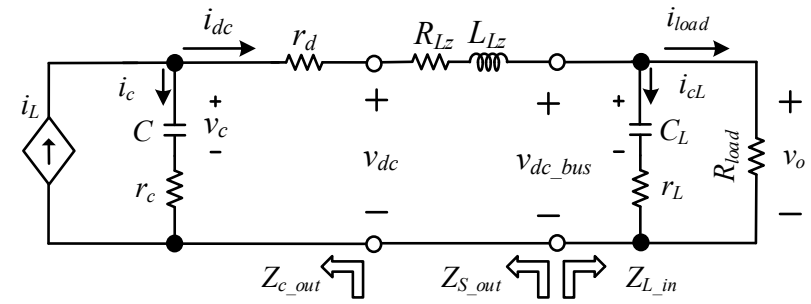

Fig. 5. Equivalent circuit of one source and one load with a line impedance and droop control gain.

- $i_{\text {Load } 1}$ and $i_{\text {Load } 2}$ are the load currents,

- $R_{L}$ and $R_{C P L}$ are the resistive loads.

The system parameters of the DC microgrid considered (in Fig. 2) are listed in Table I.

\section{B. DC voltage-source converters}

To supply the power to the DC microgrid, different structures of the DC VSC, such as AC/DC PWM converters, rectifiers with back-end DC/DC converters, and DC/DC converters, can be employed, as shown in Fig. 3. In this work, it is assumed that the diode rectifier with a back-end DC/DC converter supplies the DC power, where the output voltage of the rectifier is regarded as constant due to its large output capacitor. Therefore, the output of the AC/DC PWM converter is regarded as a voltage source as shown in Fig. 2.

To provide the stable DC voltage, the output voltage of the DC VSC is controlled with an inner current control loop and an outer voltage control loop. During the parallel operation of multiple DC VSCs, the droop control is usually employed for sharing of the power and current. Fig. 4(a) shows the control block diagram of the V/I droop-controlled DC VSC, where the LPF is used for the droop control [6], [7]. The $v_{d c n}$ and $v_{d c}$ are the nominal DC-bus voltage and the output voltage of the VSC, respectively, $i_{L}$ is the input current of the VSC, $i_{d c}$ is the output current of the source side flowing through the line impedance and $r_{d}$ is the droop controller gain.

In Fig. 4(a), the behavior of the current control loop can be simplified as an LPF since the BW of the current control loop is sufficiently higher than that of the voltage control loop [26][29]. Then, the DC VSC can be modelled as a current source with a parallel capacitor, which is shown in Fig. 4(b), where the droop controller and voltage controller are not included and $r_{c}$ means the small equivalent series resistance (ESR) of the capacitor [27], [29]. Fig. 5 shows the equivalent circuit of one source converter and one load with a line impedance and a droop control gain, from which electrical equations of the system can be expressed as

$$
\begin{gathered}
L_{L z} \frac{d i_{d c}}{d t}=v_{c}+r_{c} i_{L}+\left(-r_{c}-r_{d}-R_{L Z}\right) i_{d c}-v_{d c_{-} b u s}, \\
C \frac{d v_{c}}{d t}=i_{L}-i_{d c},
\end{gathered}
$$

where $L_{L z}$ and $R_{L z}$ are the line inductance and resistance, respectively.

\section{Loads}

The different types of loads are connected to the DC bus, which can be classified into constant power load (CPL), constant impedance load (CIL) and constant current load (CCL) [30], [31]. In DC power systems, the CPL affects the voltage stability dominantly since its input impedance is negative which varies according to the operating condition [31], [32]. The input impedance of the CPL at an operating point can be expressed as [31]

$$
R_{C P L}=-V_{L}^{2} / P_{L},
$$

where the $P_{L}$ and $V_{L}$ are the power and voltage at the input terminal of the load at operating point, respectively. In this work, a CPL and a resistive load which is a type of CIL are involved, which are shown in Fig. 2.

\section{DC bus capacitor}

In Fig. 5, if the ESR of input capacitor on the load side, rL, is neglected, the voltage across the DC-bus capacitor can be expressed as

$$
C_{L} \frac{d v_{C L}}{d t}=i_{d c}-\left(v_{d c_{\text {_bus }}} / R_{\text {Load }}\right),
$$

where $C_{L}$ and $R_{\text {Load }}$ are the capacitance and resistance on the load side, respectively.

\section{STABILITY ANALYSIS OF DC MICROGRIDS}

\section{A. Passivity-based stability analysis}

To guarantee the reliability or quality of the bus voltage of the distributed DC power system, stability analysis should be 
carried out. Conventionally, the stability analysis is performed with the forbidden-region-based method using Nyquist contour of the impedance ratio between the source and load such as Middlebrook Criterion, Gain and Phase Margin Criterion, Energy Source Analysis Consortium (ESAC) Criterion and so on [33]. On the other hand, a passivity-based stability analysis method was proposed in [34], which is effective for the applications that a bi-directional power flow exists due to the change of operating mode or system reconfiguration.

For the passivity-based stability analysis, the impedance of the one-port system is needed, which can be expressed as [34]

$$
Z_{\text {bus }}(s)=\frac{V_{\text {bus }}(s)}{I_{\text {bus }}(s)}=Z_{1} / / Z_{2} / / \ldots Z_{n} / / \ldots Z_{n+m},
$$

where $Z_{\text {bus }}$ is the total bus impedance and $Z_{l}$ to $Z_{n+m}$ are the input and output impedances of the subsystems ( $n$ source converters and $m$ load converters), $V_{b u s}$ and $I_{b u s}$ are bus voltage and bus current, respectively.

If a system can only absorb energy, it is considered as passive, for which the necessary and sufficient conditions of the oneport system with $Z_{b u s}$ can be expressed as

$$
\int_{-\infty}^{t} v_{b u s}(\tau) i_{b u s}(\tau) d t \geq 0, \text { for all } t .
$$

For the linear time-invariant (LTI) system, the system is stable if and only if the following conditions are satisfied as [34]

- $Z_{\text {bus }}(s)$ includes no right half-plane poles.

$\cdot \operatorname{Re}\left\{Z_{\text {bus }}(j \omega)\right\} \geq 0$ or $-90^{\circ} \leq \angle Z_{\text {bus }}(j \omega) \leq 90^{\circ}, \forall \omega$.

\section{B. Bus impedance}

To derive the bus impedance, the output impedance of the source and the input impedance of the load are required. Fig. 5 shows the equivalent circuit of one source and one load with a line impedance and droop control gain, where the voltage control loop is excluded.

From Fig. 4 and Fig. 5, the output impedance of the DC VSC with a droop controller $\left(Z_{c_{-} \text {out }}\right)$ can be expressed by applying the Mason's gain formula as [35],

$$
Z_{c_{-} \text {out }}=-\frac{v_{d c}}{i_{d c}}=\frac{H_{d}(s) H_{v}(s) H_{c}(s) G_{c}(s)+G_{c}(s)}{1+\left(H_{v}(s) H_{c}(s) G_{c}(s)\right)},
$$

where

$$
\begin{gathered}
H_{d}(s)=r_{d} \frac{\omega_{f d}}{s+\omega_{f d}}, \\
H_{v}(s)=\frac{k_{p v} s+k_{i v}}{s} \frac{\omega_{f v}}{s+\omega_{f v}}, \\
H_{c}(s)=\frac{\omega_{c}}{s+\omega_{c}},
\end{gathered}
$$

(a)

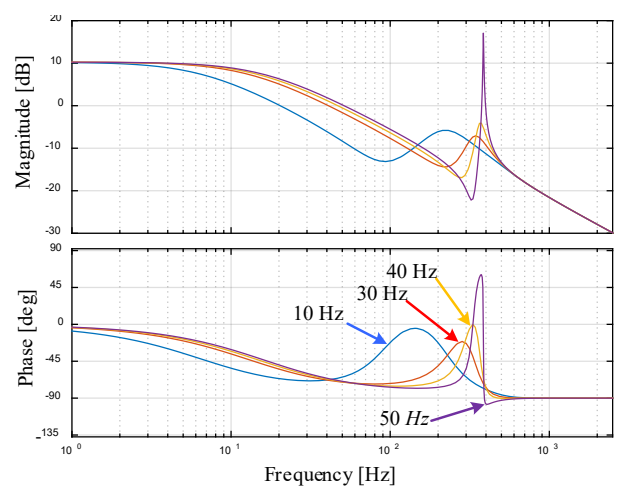

(b)

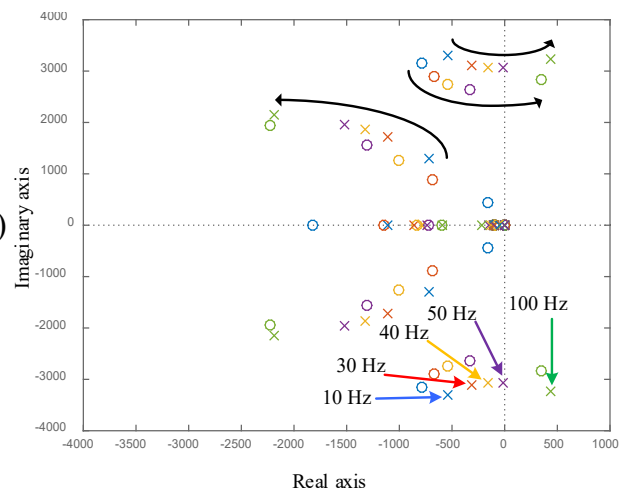

Fig. 6. Influences of the low pass filter used for droop control on bus impedance $\left(f_{d}: 10 \mathrm{~Hz} \rightarrow 100 \mathrm{~Hz}\right)$. (a) Bode plot, (b) Pole-zero map.

$$
G_{c}(s)=\frac{1}{C s},
$$

where $\omega_{f d}$ and $\omega_{f v}$ are the cut-off frequencies of the LPF, $k_{p v}$ and $k_{i v}$ are the PI gains of voltage controller, $\omega_{c}$ is the BW of the current control loop, $r_{L}$ is the ESR of the capacitor. In addition, the output impedance of the source side including the line impedance, $Z_{S_{-} \text {out }}$, can be expressed as

$$
Z_{S_{-} \text {out }}=Z_{c_{-} \text {out }}+s L_{L z}+R_{L z} \text {. }
$$

For a resistive load, the input impedance of the load side can be expressed as

$$
Z_{L_{-} \text {in }}=\frac{v_{d c_{-} \text {bus }}}{i_{d c}}=\frac{R_{\text {load }}}{s C_{L} R_{\text {load }}+1} .
$$

In addition, $R_{\text {load }}$ can be substituted by $R_{C P L}$ from (3) in term of CPL.

By substituting (12) and (13) into (5), the impedance of the bus with one source and one load is obtained as

$$
Z_{\text {bus }}(s)=Z_{S_{-} \text {out }} / / Z_{L_{-} \text {in }} \text {. }
$$

\section{Effects of system parameters}


(a)

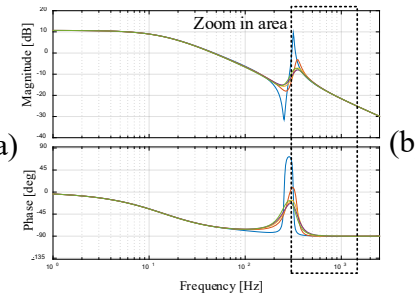

(b)

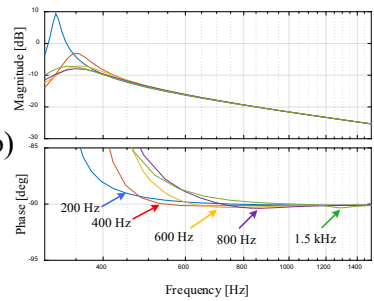

(c)

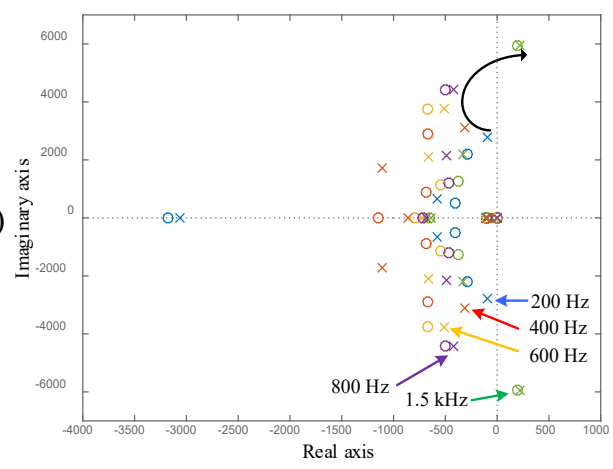

Fig. 7. Influences of the bandwidth of voltage control loop on bus impedance $\left(f_{v c}: 200 \mathrm{~Hz} \rightarrow 1.5 \mathrm{kHz}\right.$ ) (a) Bode plot, (b) Bode plot (zoom-in), (c) Pole-zero map.

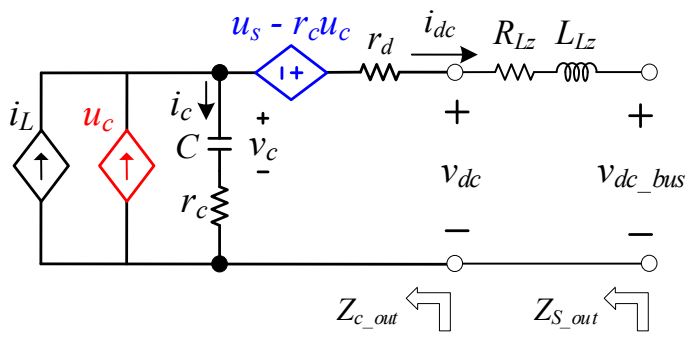

Fig. 8. Equivalent circuit of the simplified source converter with imaginary voltage and current sources

The influences of system parameters on the bus voltage stability of the DC power system have been investigated in the previous studies [6], [7], [9], [12], [37], [38]. In this work, the influences of the cut-off frequency of the feedback filter (LPF) used for droop control and BW of the voltage control loop are examined for the passivity-based stability analysis.

Fig. 6 shows the effects of the LPF used for droop control on the bus impedance with one source and one CPL. Fig. 6(a) and (b) show the Bode plot and the pole-zero map of the bus impedance. When the cut-off frequency is $50 \mathrm{~Hz}$, the phase is lower than $-90^{\circ}$ near $400 \mathrm{~Hz}$. In this case, the passivity condition of the bus impedance is not satisfied even though there are no right half-plane poles as shown in Fig. 6(b). On the other hand, when the cut-off frequency is lower than $40 \mathrm{~Hz}$, the passivity condition is satisfied.

Fig. 7 shows the influences of the BW of the voltage control loop on the bus impedance with one source and one CPL. Fig. 7(a) shows the Bode plot of the bus impedance and its zoom-in plot between $200 \mathrm{~Hz}$ and $1.5 \mathrm{kHz}$ is shown in Fig. 7(b). As can be seen, the higher BW of the voltage control loop of the power converter cause instability. When the BW is set as $600 \mathrm{~Hz}$, the passivity condition is not satisfied since the phase near the $\mathrm{BW}$ frequency is slightly below $-90^{\circ}$. In Fig. 7(c), there are right half-plane poles when the BW is selected as $1.5 \mathrm{kHz}$.

\section{IDA-PBC BASED ACTIVE DAMPING CONTROL}

\section{A. Introduction of IDA-PBC theory}

The network representation of a non-resistive system with independent storage elements that interact with its environment leads to the mathematical model of a port-controlled Hamiltonian system (PCHS). The PCHS form can be expressed as [18], [39]

$$
\begin{gathered}
\dot{x}=[J(x)-R(x)] \frac{\partial H(x)}{\partial x}+g(x) u+\varepsilon, \\
y=g^{T}(x) \frac{\partial H(x)}{\partial x},
\end{gathered}
$$

where $J(x)$ and $R(x)$ are the interconnection and the dissipation matrices $\left(J(x)=-J^{T}(x), R(x)=R^{T}(x)\right)$, respectively, $H(x)$ is the Hamiltonian function, $\varepsilon$ is the disturbance matrix, $g$ is the external-port connection matrix, $u$ is the control input, and $y$ is the output of the system. The superscript $T$ means the transpose of the matrix.

The goal of the interconnection and damping assignment passivity-based control (IDA - PBC) is to find a state feedback control law, $u=\beta(x)$, such that the closed-loop dynamics is a PCHS with a dissipation [18].

\section{B. Design of proposed damping control based on IDA-PBC}

To damp the oscillatory components of power and current, the imaginary voltage source $\left(u_{s}-r_{c} u_{c}\right)$ and current sources $\left(u_{c}\right)$ are newly added to the equivalent circuit of Fig. 5 , which results in Fig. 8. By adding these imaginary voltage and current sources, the power and current oscillations can be compensated effectively without a modification of the basic structure of voltage and current control loops.

From Fig. 8, the dynamic equations of the current and voltage oscillatory components can be expressed as

$$
\begin{gathered}
L_{L z} \frac{d \tilde{i}_{d c}}{d t}=\left(-r_{d}-r_{c}-R_{L Z}\right) \tilde{i}_{d c}+\tilde{v}_{c}+u_{s}-\tilde{v}_{d c_{-} b u s}+r_{c} \tilde{i}_{L} \\
C \frac{d \tilde{v}_{c}}{d t}=-\tilde{i}_{d c}+u_{c}+\tilde{i}_{L}
\end{gathered}
$$

where the superscript ' $\sim$ ' denotes the oscillatory components.

From (17) and (18), the state variables for the PCHS can be set as 


$$
x=\left[\begin{array}{c}
L_{L z} \tilde{i}_{d c} \\
C \tilde{v}_{c}
\end{array}\right]=\left[\begin{array}{cc}
L_{L z} & 0 \\
0 & C
\end{array}\right]\left[\begin{array}{c}
\tilde{i}_{d c} \\
\tilde{v}_{c}
\end{array}\right]=\mathrm{D}\left[\begin{array}{c}
\tilde{i}_{d c} \\
\tilde{v}_{c}
\end{array}\right],
$$

where,

$$
\mathrm{D}=\left[\begin{array}{cc}
L_{L z} & 0 \\
0 & C
\end{array}\right] .
$$

The control inputs are selected as

$$
u=\left[\begin{array}{ll}
u_{s} & u_{c}
\end{array}\right]^{T},
$$

and the output variables are expressed as

$$
y=\left[\begin{array}{ll}
\tilde{i}_{d c} & \tilde{v}_{c}
\end{array}\right]^{T} .
$$

Then, the Hamiltonian function can be set as

$$
H(x)=\frac{1}{2} x^{T} D^{-1} x=\frac{1}{2 L_{L Z}} \tilde{i}_{d c}^{2}+\frac{1}{2 C} \tilde{v}_{c}^{2} .
$$

From (15) to (23), the PCHS form of the oscillatory components in the DC VSC is derived as

$$
\begin{gathered}
\dot{x}=[J(x)-R(x)] \frac{\partial H(x)}{\partial x}+g(x)\left[\begin{array}{l}
u_{s} \\
u_{c}
\end{array}\right]+\varepsilon, \\
y=g^{T}(x) \frac{\partial H(x)}{\partial x}=\left[\begin{array}{ll}
\tilde{i}_{d c} & \tilde{v}_{c}
\end{array}\right],
\end{gathered}
$$

where

$$
\begin{gathered}
{[J(x)-R(x)]=\left[\begin{array}{cc}
0 & 1 \\
-1 & 0
\end{array}\right]-\left[\begin{array}{cc}
r_{d}+R_{L Z}+r_{c} & 0 \\
0 & 0
\end{array}\right],} \\
\frac{\delta H(x)}{\delta x}=\mathrm{D}^{-1} x, \\
g=g^{T}=\left[\begin{array}{cc}
1 & 0 \\
0 & 1
\end{array}\right], \\
\varepsilon=\left[\begin{array}{c}
r_{c} \\
1
\end{array}\right] \tilde{i}_{L}+\left[\begin{array}{c}
-1 \\
0
\end{array}\right] \tilde{v}_{d c_{-} b u s} .
\end{gathered}
$$

To achieve the asymptotical stability at the equilibrium point, $x^{*}$, the desired dynamics of the closed-loop system, $H_{d}(x)$, can be set as

$$
H_{d}(x)=\frac{1}{2 L_{L Z}}\left(x_{1}-x_{1}^{*}\right)^{2}+\frac{1}{2 C}\left(x_{2}-x_{2}^{*}\right)^{2},
$$

where $H_{d}(x)$ is minimized at $x^{*}$. With the control law, $u=\beta(x)$, the PCHS form with a dissipation can be expressed with $J_{d}(x)$ and $R_{d}(x)$ as

$$
\dot{x}=\left[J_{d}(x)-R_{d}(x)\right] \frac{\partial H_{d}(x)}{\partial x} .
$$

To obtain the control law based on the desired Hamiltonian function, the $J_{a}(x)$ and $R_{a}(x)$ should be selected to satisfy the following conditions as

$$
\begin{aligned}
& {\left[J(x)+J_{a}(x)\right]=-\left[J(x)+J_{a}(x)\right]^{T},} \\
& {\left[R(x)+R_{a}(x)\right]=\left[R(x)+R_{a}(x)\right]^{T} \geq 0,}
\end{aligned}
$$

where,

$$
\begin{aligned}
& J_{d}(x)=J(x)+J_{a}(x), \\
& R_{d}(x)=R(x)+R_{a}(x) .
\end{aligned}
$$

If it is assumed that $\beta(x), J_{a}(x), R_{a}(x)$ and the vector function $K(x)$ can be found for the PCHS, the PDE (partial differential equation) for the desired energy function is given as [18]

$$
\begin{aligned}
& {\left[J(x)+J_{a}(x)-\left(R(x)+R_{a}(x)\right)\right] K(x),} \\
& =-\left[J_{a}(x)-R_{a}(x)\right] \frac{\partial H(x)}{\partial x}+g \beta(x)+\varepsilon
\end{aligned},
$$

where a vector function $K(x)$ should satisfy the following conditions as

$$
\begin{gathered}
\frac{\partial K}{\partial x}(x)=\left[\frac{\partial K}{\partial x}(x)\right]^{T}: \text { Integrality, } \\
K\left(x^{*}\right)=-\frac{\partial H}{\partial x}\left(x^{*}\right): \text { Equilibrium assignment, } \\
\frac{\partial K}{\partial x}\left(x^{*}\right)>-\frac{\partial^{2} H}{\partial x^{2}}\left(x^{*}\right): \text { Lyapunov stability. }
\end{gathered}
$$

If these conditions are satisfied, the closed-loop system becomes a PCH form with a dissipation, where

$$
H_{d}(x)=H(x)+H_{a}(x) .
$$

To satisfy the conditions of (37) to (39), the $K(x)$ can be set as [40]

$$
K(x)=\frac{\delta H_{a}(x)}{\delta x}=\frac{\delta H_{d}(x)}{\delta x}-\frac{\delta H(x)}{\delta x}=-D^{-1} x .
$$

Also, let's choose the $J_{a}(x)$ and $R_{a}(x)$ as

$$
J_{a}(x)=\left[\begin{array}{cc}
0 & -1 \\
1 & 0
\end{array}\right], R_{a}(x)=\left[\begin{array}{cc}
k_{1} & 0 \\
0 & k_{2}
\end{array}\right],
$$

where $k_{1}$ and $k_{2}$ are the damping controller gains.

Meanwhile, in Fig. 8, the oscillatory components in the capacitor voltage and output voltage of the DC VSC are regarded as equal due to the low value of $r_{c}$. Then, from (36), the control law, $\beta(x)=\left[u_{s}, u_{c}\right]^{T}$, for damping of power and current oscillations is derived as

$$
\begin{gathered}
u_{s}=-k_{1} \tilde{i}_{d c}-\tilde{v}_{d c}-r_{c} \tilde{i}_{L}+\tilde{v}_{d c_{-} b u s}, \\
u_{c}=\tilde{i}_{d c}-k_{2} \tilde{v}_{d c}-\tilde{i}_{L},
\end{gathered}
$$

where $\tilde{i}_{d c}, \tilde{v}_{d c}, \tilde{i}_{L}$, and $\tilde{v}_{d c \_b u s}$ are the high-pass filtered quantities of each signal. 


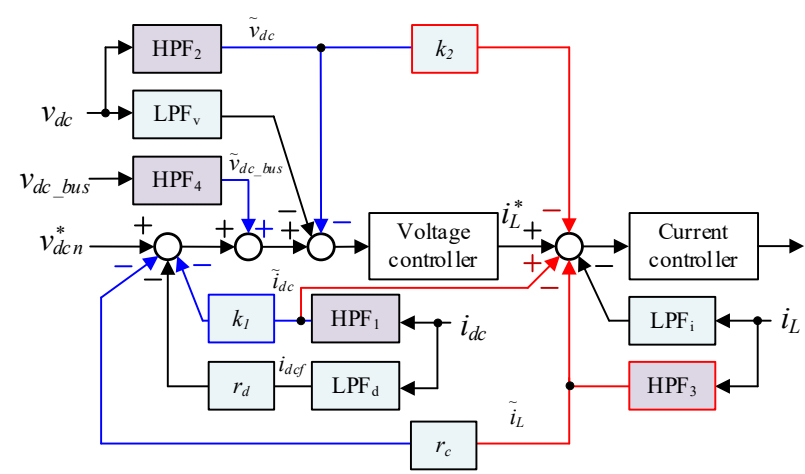

Fig. 9. Block diagram of the proposed damping control.

By adding (43) and (44) to the voltage and current references, respectively, the new references $\left(v_{d c d}{ }^{*}, i_{L d}{ }^{*}\right)$ for damping are obtained as

$$
\begin{gathered}
v_{d c d}{ }^{*}=v_{d c}{ }^{*}+u_{s}=v_{d c n}{ }^{*}-r_{d} i_{d c f}+u_{s}, \\
i_{L d}{ }^{*}=i_{L}{ }^{*}+u_{c},
\end{gathered}
$$

where $i_{d c f}$ is the low-pass filtered quantity of $i_{d c}$.

Fig. 9 shows the block diagram of the proposed damping control for the DC VSC. The voltage and current controllers are used to regulate the output voltage and inner current, respectively. The additional control inputs for damping $\left(u_{s}\right.$ and $\left.u_{c}\right)$ are added to the voltage and current references. The droop control is used to balance the power and current between the VSCs. The high-pass filters, $\mathrm{HPF}_{1}$ to $\mathrm{HPF}_{4}$, are used to acquire the oscillatory components of the feedback signals. To eliminate the switching-frequency ripples in feedback signals, the cut-off frequency of the $\mathrm{LPF}_{\mathrm{v}}$ and $\mathrm{LPF}_{\mathrm{i}}$ is set as one tenth of the switching frequency. For droop control, an $\mathrm{LPF}_{\mathrm{d}}$ is used to eliminate the high frequency components. The cut-off frequencies of filters are listed in Table I.

From Fig. 8 and Fig. 9, the output impedance of the DC VSC can be derived as

$$
\begin{gathered}
z_{s_{-} \text {out }}=\frac{v_{\text {dcbus }}}{i_{o}} \\
=\left[\begin{array}{l}
1+H_{c}(s) H_{h c}(s)\left(1+r_{c} H_{v}(s)\right)+G_{c}(s) G_{L Z}(s)\left[1+H_{c}(s) H_{h c}(s)\left(1+r_{c} H_{v}(s)\right)\right] \\
-G_{c}(s) G_{L Z}(s) H_{c}(s)\left[H_{H f \mathcal{c}}(s)-H_{v}(s)\left\{k_{1} H_{h f c}(s)+H_{d}(s)\right\}\right] \\
-G_{c}(s) H_{c}(s)\left[-k_{2} H_{h f v}(s)-H_{v}(s)\left\{1+H_{h j}(s)\right\}\right]
\end{array}\right] \\
G_{L Z}(s)\left[1+H_{c}(s) H_{h c}(s)\left(1+r_{C} H_{v}(s)\right)\right]-H_{h j p h}(s) H_{v}(s) G_{c}(s) G_{L Z}(s) H_{c}(s)
\end{gathered}
$$

where $H_{h f v}(s), H_{h f v b}(s), H_{h c}(s)$, and $H_{h f c}(s)$ are the transfer functions of the high-pass filters for output voltage $\left(v_{d c}\right)$, DCbus voltage $\left(v_{d c_{-} \text {bus }}\right)$, output current $\left(i_{d c}\right)$ and input current $\left(i_{L}\right)$, respectively, and $G_{L Z}(s)$ is that of the line impedance.

\section{Stability of the proposed damping control}

From (27), (30) and (41), if $x$ is equal to $x^{*}$, the following conditions are obtained as (a)
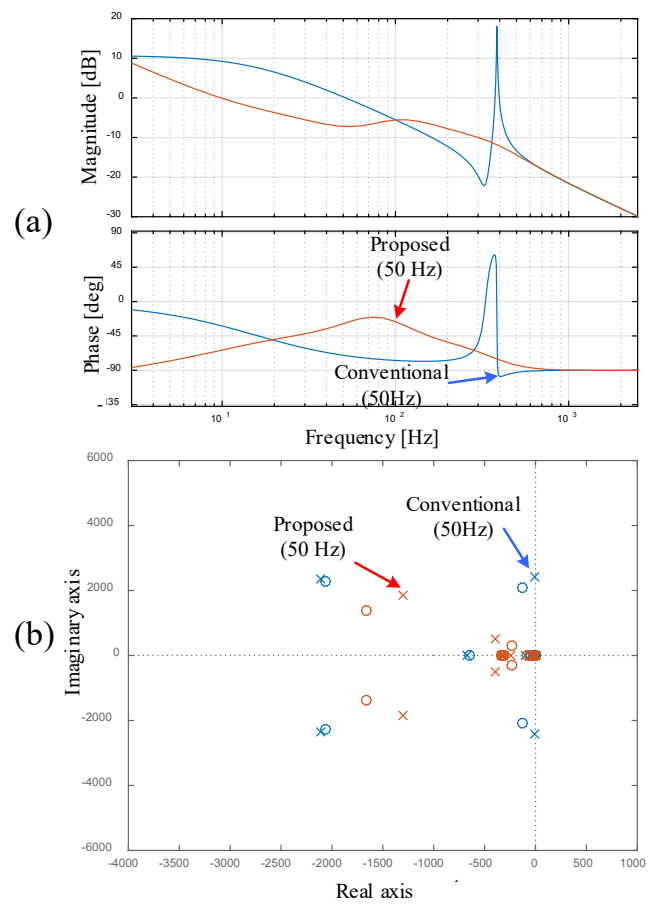

Fig. 10. Influences of the LPF used for droop control on bus impedance (a) Bode plot, (b) Pole-zero map.

$$
\begin{gathered}
\frac{\delta H_{d}(x)}{\delta x}=D^{-1}\left(x-x^{*}\right)=0, \\
\frac{\partial^{2} H_{d}}{\partial x^{2}}(x)=D^{-1}>0 .
\end{gathered}
$$

Then, the condition of (39) is satisfied, so that the system is asymptotically stable.

\section{Gain selection technique}

As can be seen in (43) and (44), there are two gains $\left(k_{1}, k_{2}\right)$ for the proposed controller. The basic conditions for determining these gains are given in (32) and (33). However, it is necessary to perform repetitive time-domain simulations in order to obtain satisfactory performances. To avoid this trouble, a gain selection technique is developed as follows.

By substituting (43) and (44) into (24), the system dynamic equation for damping control is obtained as

$$
\dot{x}=\left[\begin{array}{cc}
\frac{-r_{d}-R_{L Z}-r_{c}-k_{1}}{L_{L z}} & 0 \\
0 & -k_{2} / C
\end{array}\right] x .
$$

From (50), then, the characteristic equation can be expressed as

$$
s^{2}-\left(\frac{-r_{d}-R_{L Z}-r_{c}-k_{1}}{L_{L z}}+\frac{-k_{2}}{C}\right) s+\frac{\left(r_{d}+R_{L Z}+r_{c}+k_{1}\right) k_{2}}{L_{L z} C}=0 .
$$

When (51) is compared with the standard second-order form as 
(a)
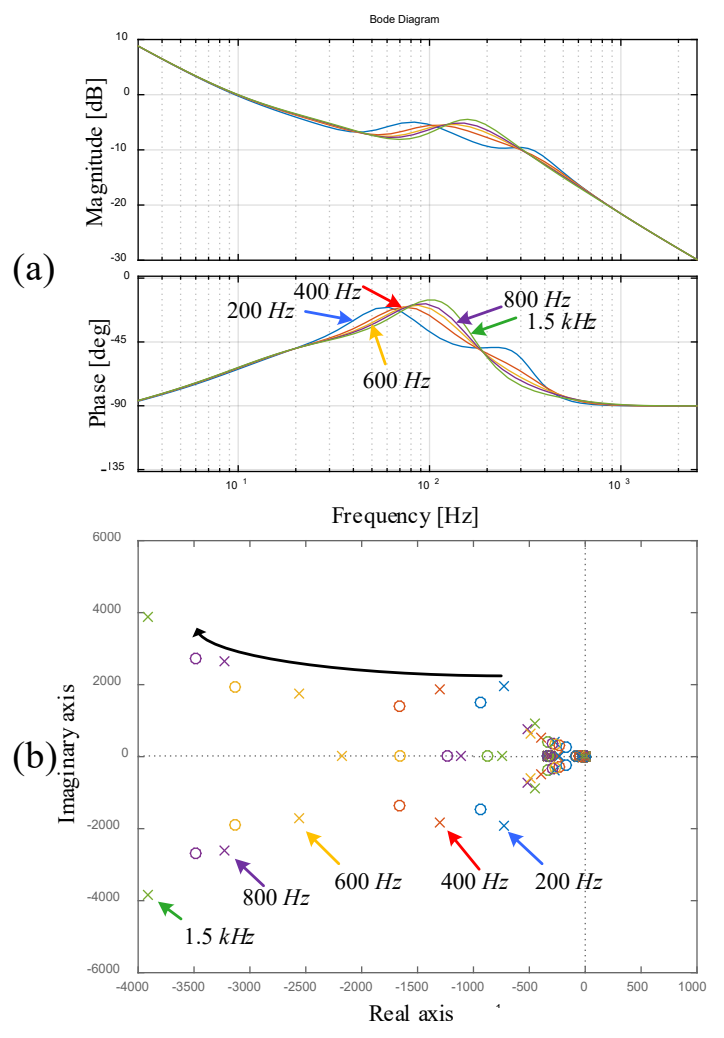

Fig. 11. Influences of the BW of voltage control loop on bus impedance (a) Bode plot, (b) Pole-zero map.

$$
s^{2}+2 \zeta \omega_{n}+\omega_{n}^{2}=0
$$

the damping ratio $\zeta$ and natural frequency $\omega_{n}$ for the PCHS are expressed, respectively, as

$$
\begin{gathered}
\omega_{n}=\sqrt{\frac{-r_{d}-R_{L Z}-r_{c}-k_{1}}{L_{L z}} \cdot \frac{-k_{2}}{C}}, \\
\zeta=\left(\frac{r_{d}+R_{L Z}+r_{c}+k_{1}}{2 L_{L z}}+\frac{k_{2}}{2 C}\right) / \sqrt{\frac{-r_{d}-R_{L Z}-r_{c}-k_{1}}{L_{L z}} \cdot \frac{-k_{2}}{C}} .
\end{gathered}
$$

From (51) and (52), then, the resultant controller gains are given by

$$
\begin{aligned}
& k_{1}=\frac{L_{L z} C \omega_{n}^{2}}{k_{2}}-\left(r_{d}+R_{L Z}+r_{c}\right), \\
& k_{2}=\omega_{n} C \zeta \pm \sqrt{\left(\omega_{n} C \zeta\right)^{2}-C^{2} \omega_{n}^{2}} .
\end{aligned}
$$

In (55) and (56), the natural frequency, $\omega_{n}$, needs to be equal to or lower than the BW of the voltage control loop. In addition, the damping ratio can be set as unity in order to avoid overshoots.

\section{E. Bus impedance analysis with proposed control method}

In this subsection, the effects of the proposed active damping control method are investigated, where $f_{l}$ to $f_{4}$ are set as $3 \mathrm{~Hz}$,

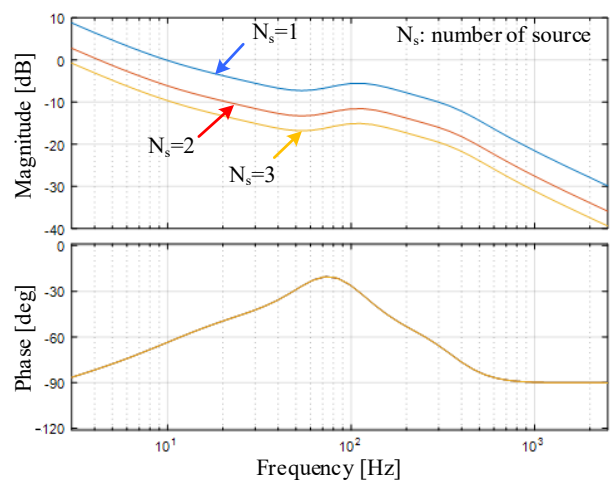

Fig. 12. Effects of the multiple sources on bus impedance.

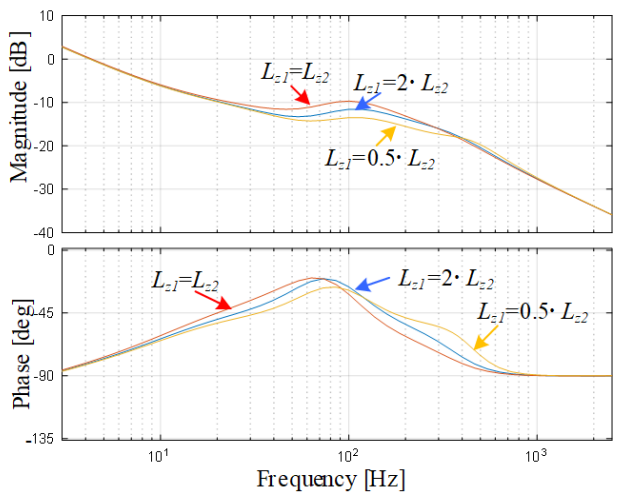

Fig. 13. Effects of different line impedances for twosource and a-CPL bus system.

the natural frequency $\omega_{n}$ of the controller is set equal to the BW of the voltage control loop and the damping ratio $\zeta$ is set as 1 .

Fig. 10(a) and (b) show the Bode plot and pole-zero map of the bus impedance of the conventional and proposed methods when $f_{d}$ is $50 \mathrm{~Hz}$. For the conventional method, the passivity condition of the bus impedance is not satisfied, whereas it is satisfied for the proposed control due to the phase compensation near $400 \mathrm{~Hz}$. In addition, it is shown that there are no right halfplane poles. In the proposed method, it can be seen that the poles located closely to the right half-plane move to the left half-plane far away, as shown in Fig 11(b).

Fig. 11 shows the effects of the BWs of the voltage control loop when they are set as $200 \mathrm{~Hz}, 400 \mathrm{~Hz}, 600 \mathrm{~Hz}$ and $800 \mathrm{~Hz}$. As known from Fig. 7, when the BW of the voltage control loop is high, the passivity condition is not satisfied. However, even when the control BW is high for the proposed method, the passivity condition is satisfied due to the phase compensation, as shown in Fig. 11(a). Also, the poles move to the left halfplane further from the imaginary axis, as shown in Fig. 11(b).

Fig. 12 shows the Bode plot of the bus impedance as the number of sources $\left(N_{s}\right)$ is increased, where the line impedances for each source side are assumed to be the same. It can be seen that the magnitude (dB) is decreased as $N_{s}$ is increased, but the phase is unchanged. So, it is confirmed that the proposed controller satisfies the passivity condition even when more sources are connected. 


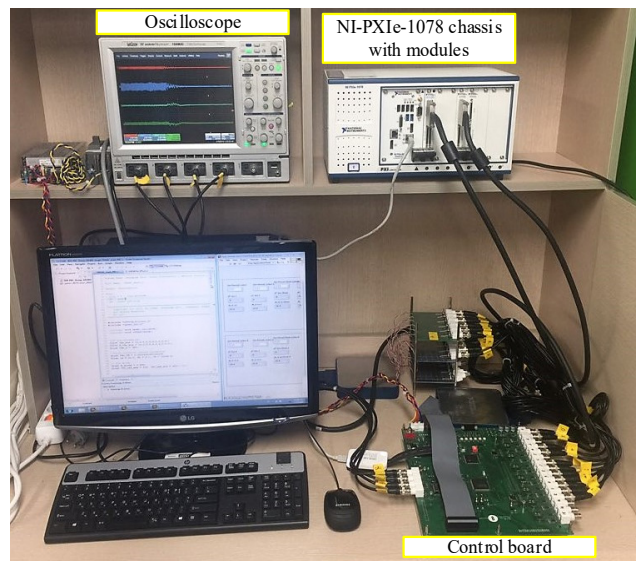

Fig. 14. Hardware-in-the-loop simulation setup.

Fig. 13 shows the Bode plots of the bus impedance for a twosource and one-CPL bus system, where it is assumed that two line impedances are different. The phase is changed due to the difference of the two line impedances, however, the value still stays within the stable range which satisfies the passivity condition. Although analysis results for output capacitance variation are not shown due to space limit, it is observed that its influence on the passivity condition of bus impedance is relatively less significant.

The DC-bus impedance in (47) includes controller gains $\left(k_{1}\right.$ and $k_{2}$ ). If $k_{1}$ or $k_{2}$ are selected inappropriately, the system becomes unstable since the passivity condition is not satisfied.

\section{RESULTS OF HARDWARE IN-THE-LOOP SIMULATION}

To verify the proposed control scheme, the HILS has been carried out. Fig. 14 shows the HILS setup which is composed of NI-PXIe-1078 chassis with modules (PXIe-1078, 8840, 7821R, PXI-6723), and laboratory control boards. The control board was designed with the DSP (TI-TMS320F28335), FPGA (XILINX-XC3S400-PQ208), analog-to-digital converter (MAX11056) and etc. The microgrid model (Fig. 2) was implemented by the Labview 2016 [41]. The DC VSCs were realized with the boost converters. The load consists of a buck converter (CPL load) and a resistor. The system parameters are listed in Table I. The PI gains of the voltage and current controllers were found based on the small signal analysis for the converter model [42], where the proportional and integral gains of the voltage controller are 2.5 and 1508; those values of the current controller are 23 and 1162. The damping controller gains are determined from (55) and (56) as $k_{1}=-2.1$ and $k_{2}=$ 2.5.

Firstly, the dynamic responses of the DC microgrid without and with the proposed damping controller are illustrated in Fig. 15 and Fig. 16, respectively. The load is changed from 0.2 p.u. to 0.8 p.u. and back to 0.2 p.u. In the steady state, control performances of DC microgrid without and with the proposed damping controller are almost similar, which provides a sufficient power to the CPL and resistive load. The deviation in the DC-bus voltage is kept within $10 \%$ of the nominal value of $380 \mathrm{~V}$, as shown in Fig. 15(b) and 16(b). When the load power

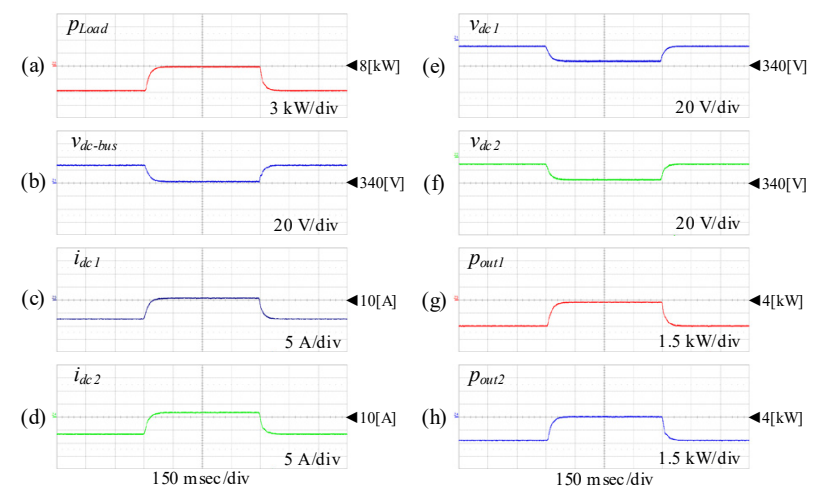

Fig. 15. Dynamic responses of DC microgrid without proposed damping controller. $\left(f_{d}: 40 \mathrm{~Hz}, f_{v c}: 400 \mathrm{~Hz}, C: 1000\right.$ $\left.\mu \mathrm{F}, C_{b}: 2000 \mu \mathrm{F}\right)$
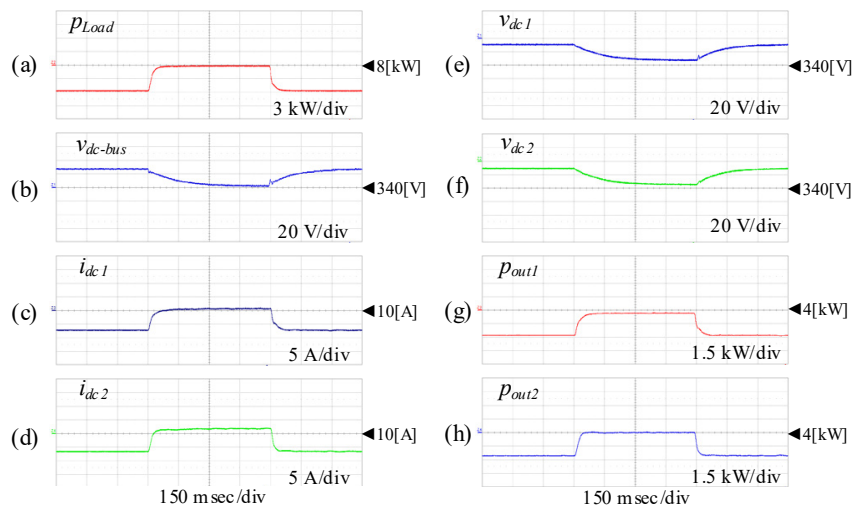

Fig. 16. Dynamic responses of DC microgrid with proposed damping controller. $\left(f_{d}: 40 \mathrm{~Hz}, f_{v c}: 400 \mathrm{~Hz}, C: 1000 \mu \mathrm{F}, C_{b}\right.$ : $2000 \mu \mathrm{F})$

is increased, the output current is increased $\left(i_{d c l}\right.$ and $\left.i_{d c 2}\right)$ but the output voltage is decreased by the droop control. In the transient state, the settling time of the $v_{d c-b u s}$ is longer than that of in Fig. 15 due to the influence of the damping control [31], which is shown in Fig. 16. However, it has no negative effect on the transient response of output currents as shown in Fig. 16(c) and (d). So, the transient responses in the supplied power $\left(p_{\text {out }}\right.$ and $\left.p_{\text {out } 2}\right)$ are not different between two methods.

Secondly, superiority of the proposed controller is demonstrated for parameter variations. Four cases of parameter change are investigated: the cut-off frequency of the LPF for droop control $\left(f_{d}\right)$, the BW of the voltage control loop $\left(f_{v c}\right)$, the output capacitance of the DC VSCs $\left(C: C_{l}, C_{2}\right)$, and the DC-bus capacitance $\left(C_{b}=C_{L I}+C_{L 2}\right)$. The change in the load power is made by varying the load resistance $\left(R_{C P L}\right)$.

Fig. 17 illustrates the transient responses of the DC microgrid in the case that the LPF of the droop controller is only used without any special damping control strategy. The load condition is changed from 0.2 p.u. to 0.8 p.u. and back to 0.2 p.u. Fig. 17(i) shows the results when $f_{\mathrm{d}}$ is $50 \mathrm{~Hz}$. The deviation of the DC-bus voltage stays within $\pm 10 \%$ of the nominal 

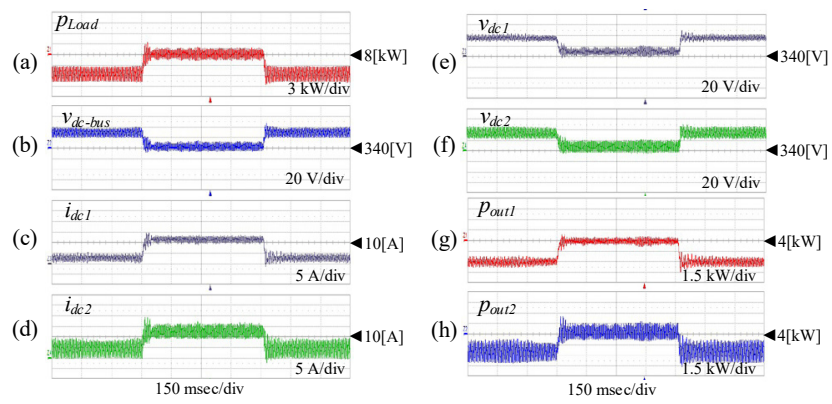

(i) $f_{d}: 50 \mathrm{~Hz}, f_{v c}: 400 \mathrm{~Hz}, C: 1000 \mu \mathrm{F}, C_{b}: 2000 \mu \mathrm{F}$
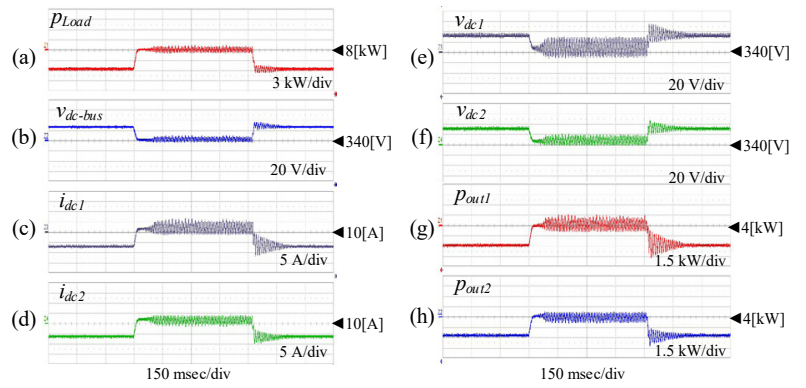

(ii) $f_{d}: 40 \mathrm{~Hz}, f_{v c}: 200 \mathrm{~Hz}, C: 1000 \mu \mathrm{F}, C_{b}: 2000 \mu \mathrm{F}$
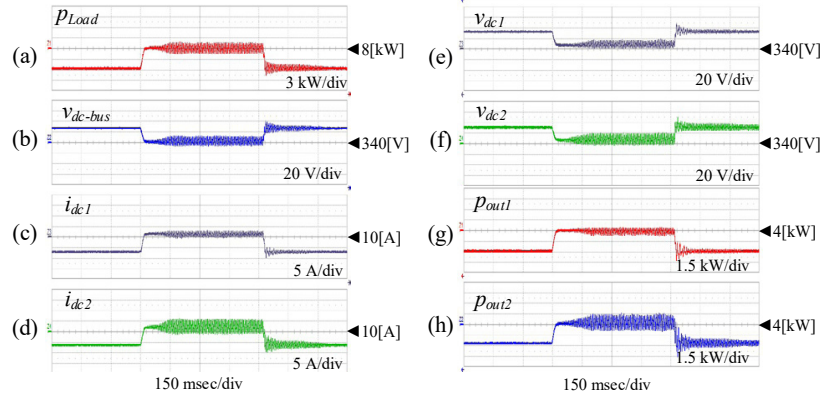

(iii) $f_{d}: 40 \mathrm{~Hz}, f_{v c}: 400 \mathrm{~Hz}, C: 2000 \mu \mathrm{F}, C_{b}: 2000 \mu \mathrm{F}$
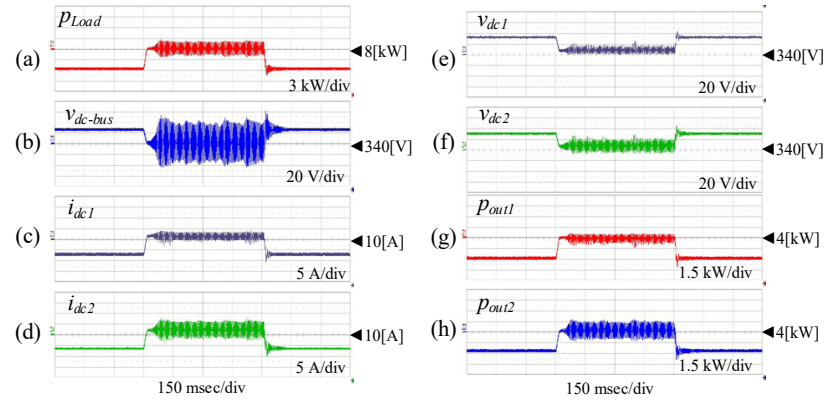

(iv) $f_{d}: 40 \mathrm{~Hz}, f_{v c}: 400 \mathrm{~Hz}, C: 1000 \mu \mathrm{F}, C_{b}: 1000 \mu \mathrm{F}$

Fig. 17. Dynamic responses of DC microgrid with LPF for droop control.
(a) Load power $\left(p_{\text {Load }}\right)$,
(e) Output voltage $\# 1\left(v_{d c 1}\right)$,
(b) DC-bus voltage $\left(v_{d c}\right.$ bus $)$,
(c) Output current \#1 (i $\left.i_{d c l}\right)$,
(d) Output current $\# 2\left(i_{d c 2}\right)$,
(f) Output voltage \#2 $\left(v_{d c 2}\right)$,
(g) Output power \#1 ( $\left.p_{\text {out }}\right)$,
(h) Output power \#2 ( $p_{\text {out } 2)}$.
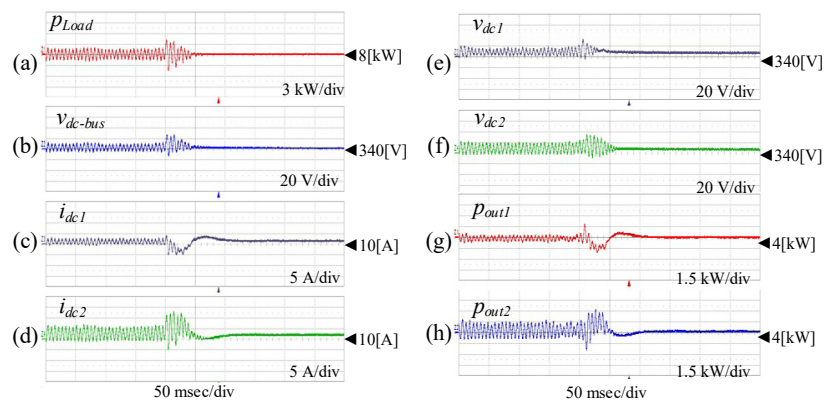

(i) $f_{d}: 50 \mathrm{~Hz}, f_{v c}: 400 \mathrm{~Hz}, C: 1000 \mu \mathrm{F}, C_{b}: 2000 \mu \mathrm{F}$
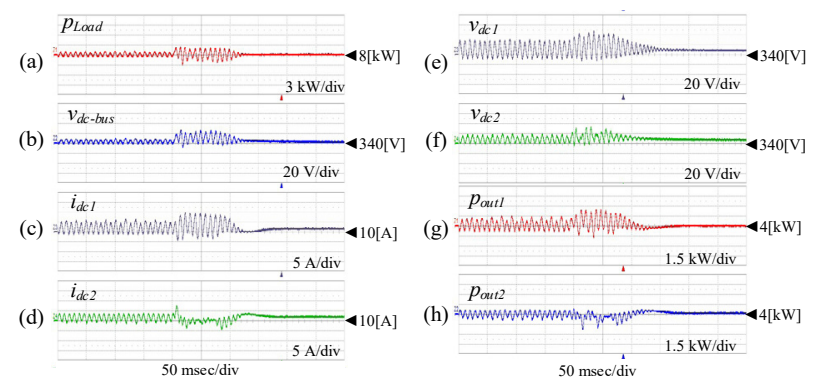

(ii) $f_{d}: 40 \mathrm{~Hz}, f_{v c}: 200 \mathrm{~Hz}, C: 1000 \mu \mathrm{F}, C_{b}: 2000 \mu \mathrm{F}$
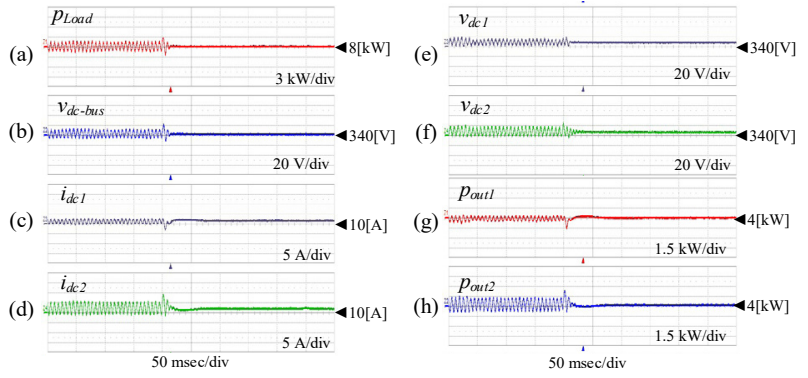

(iii) $f_{d}: 40 \mathrm{~Hz}, f_{v c}: 400 \mathrm{~Hz}, C: 2000 \mu \mathrm{F}, C_{b}: 2000 \mu \mathrm{F}$
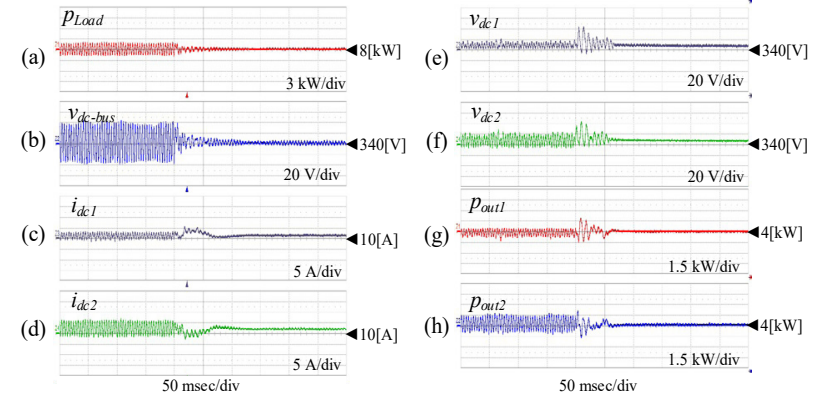

(iv) $f_{d}: 40 \mathrm{~Hz}, f_{v c}: 400 \mathrm{~Hz}, C: 1000 \mu \mathrm{F}, C_{b}: 1000 \mu \mathrm{F}$

Fig. 18. Operating performance of DC microgrid with the proposed damping control.
(a) Load power $\left(p_{\text {Load }}\right)$,
(e) Output voltage \#1 $\left(v_{d c l}\right)$,
(b) DC-bus voltage $\left(v_{d c}\right.$ bus $)$,
(c) Output current \#1 $\left(i_{d c l}\right)$,
(f) Output voltage \#2 $\left(v_{d c 2}\right)$,
(d) Output current \#2 $\left(i_{d c}\right)$,
(g) Output power \#1 ( $\left.p_{\text {out }}\right)$,
(h) Output power \#2 (pout $)$. 
TABLE II

PARAMETERS OF SMALL-SCALED DC MICROGRID

\begin{tabular}{|c|c|c|}
\hline & PARAMETERS & VALUES \\
\hline \multirow{8}{*}{$\begin{array}{c}\# 1 \& \# 2 \\
\text { DC VSC } \\
\text { (boost } \\
\text { converter) }\end{array}$} & Rated power & $400 \mathrm{~W}$ \\
\hline & Input voltage & $60 \mathrm{~V}$ \\
\hline & Output capacitor $\left(C_{l}, C_{2}\right)$ & $250 \mu \mathrm{F}$ \\
\hline & Switching / sampling freq. & $20 \mathrm{kHz} / 40 \mathrm{kHz}$ \\
\hline & Voltage control-loop BW $\left(f_{v c}\right)$ & $130 \mathrm{~Hz}$ \\
\hline & Current control-loop BW $\left(f_{c c}\right)$ & $2 \mathrm{kHz}$ \\
\hline & Droop controller gain $\left(r_{d}\right)$ & 2.5 \\
\hline & $\begin{array}{c}\text { Cut-off freq. of LPF for droop } \\
\text { control }\left(f_{d}\right)\end{array}$ & $130 \mathrm{~Hz}$ \\
\hline \multirow{3}{*}{ DC bus } & DC-bus voltage $\left(v_{d c-b u s}\right)$ & $100 \mathrm{~V}$ \\
\hline & Line impedance $Z_{L I}\left(R_{L z l}, L_{L z I}\right)$ & $16 \mathrm{~m} \Omega, 200 \mu \mathrm{H}$ \\
\hline & Line impedance $Z_{L 2}\left(R_{L z 2}, L_{L z 2}\right)$ & $30 \mathrm{~m} \Omega, 290 \mu \mathrm{H}$ \\
\hline \multirow{2}{*}{ Load side } & $\begin{array}{c}\text { Rated load power } \\
(\mathrm{CPL}+\text { resistive load })\end{array}$ & $800 \mathrm{~W}$ \\
\hline & Load capacitor $\left(C_{L 1}, C_{L 2}\right)$ & $250 \mu \mathrm{F}$ \\
\hline
\end{tabular}

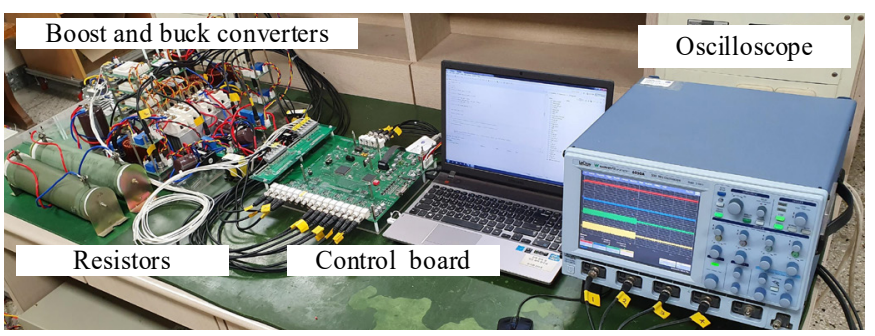

Fig. 19. Experimental setup.

voltage of $380 \mathrm{~V}$. However, large oscillatory components appear since the passivity condition is not satisfied, as expected from Fig. 6. The magnitudes of the oscillatory components in the load power and the DC-bus voltage are $3 \mathrm{~kW}$ and $20 \mathrm{~V}$, respectively, at the 0.8 p.u load conditions. Fig. 17(ii) illustrates the results when the BW of the voltage control loop $\left(f_{v c}\right)$ is set as $200 \mathrm{~Hz}$ and $f_{b}$ is kept at $40 \mathrm{~Hz}$. In this case, the passivity condition of the bus impedance is satisfied as shown in Fig. 7. Therefore, the oscillatory components of the load power and DC-bus voltage are relatively low. On the other hand, when the load is increased to $0.8 \mathrm{p} . \mathrm{u}$, the oscillatory components appear in the output current and voltage, as shown in (c) to (f) due to the low BW of the voltage control loop. Fig. 17(iii) shows the transient responses when the output capacitance of the DC VSC is set as $2000 \mu \mathrm{F}$. In general, the parameter variation such as an increase of the output capacitance makes the PI controller detuned. Therefore, the instability may happen if the operating point is changed. It is noticed that the passivity condition is not satisfied when the capacitance is increased. It is seen in (a) and (b) of Fig. 17(iii) that the oscillatory components in the load power and DC-bus voltage appear at 0.2 p.u. load. Furthermore, the oscillatory components are much increased at 0.8 p.u. load. Fig. 17(iv) illustrates the performance when the DC-bus

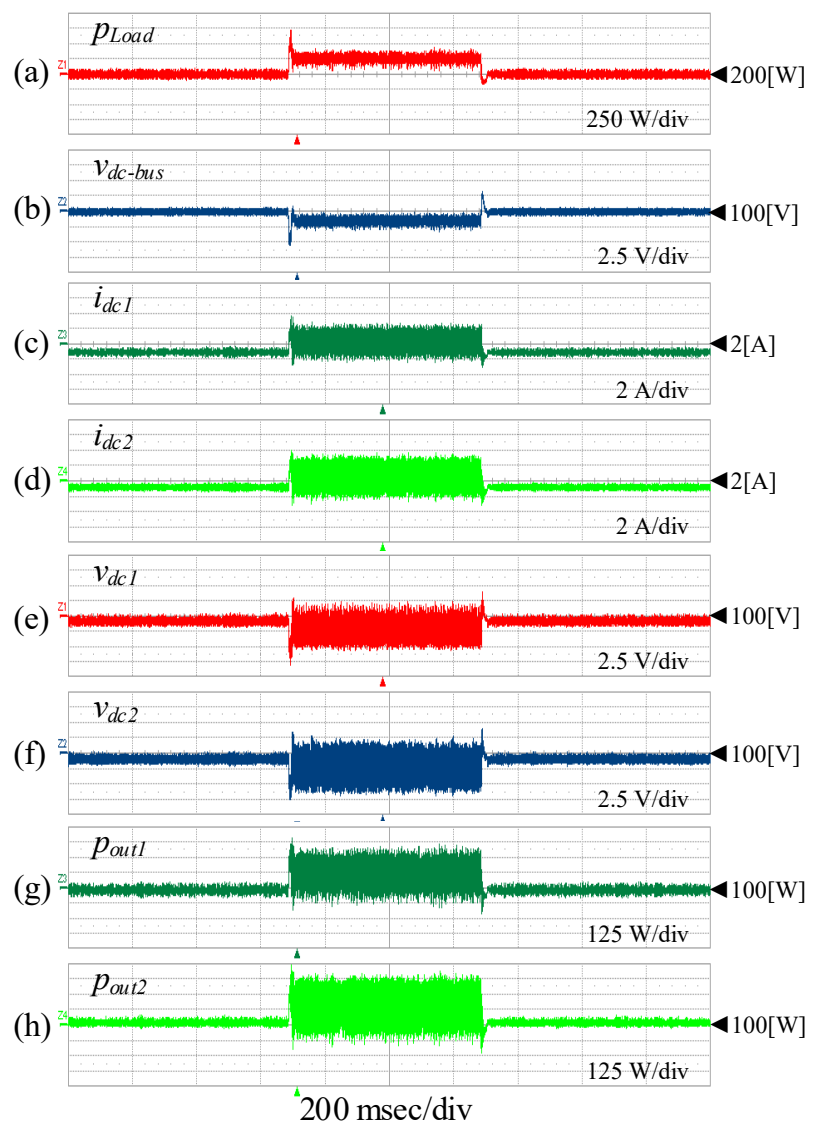

Fig. 20. Responses of DC microgrid without damping control at load changes.
(a) Load power $\left(p_{\text {Load }}\right)$,
(b) DC-bus voltage $\left(v_{d c \_b u s}\right)$,
(e) Output voltage \#1 $\left(v_{d c l}\right)$,
(c) Output current \#1 $\left(i_{d c l}\right)$,
(f) Output voltage \#2 $\left(v_{d c 2}\right)$,
(d) Output current \#2 $\left(i_{d c 2}\right)$,
(g) Output power \#1 ( $\left.p_{\text {out } 1}\right)$,
(h) Output power \#2 ( $\left.p_{\text {out } 2}\right)$.

capacitance is set as $1000 \mu \mathrm{F}$. It is seen that there are no oscillatory components at 0.2 p.u. load. However, when the load is increased to 0.8 p.u., large oscillations in the bus voltage appear as shown in (b), of which the peak-to-peak value is 80 $\mathrm{V}$.

Fig. 18 shows the operating performance of the DC microgrid, where it is initially operated without the damping control and after a while with the damping control. The load condition is 0.8 p.u. The parameter values used in the four cases of Fig. 18(i) to (iv) are set the same as those of in Fig. 17(i) to (iv), respectively. During the initial operation, the power, voltage, and current oscillations are high. However, after the proposed damping control is applied, all the oscillatory components are significantly reduced in some transient interval. In addition, it is observed that the current and power sharing between two DC VSCs are well done as shown in Fig. 18 (c) and $(\mathrm{d})$, and $(\mathrm{g})$ and $(\mathrm{h})$. In four cases of parameter change, the controller gains $\left(k_{1}\right.$ and $k_{2}$ ) have not been updated, which shows the robustness of the proposed scheme to parameter variations. 


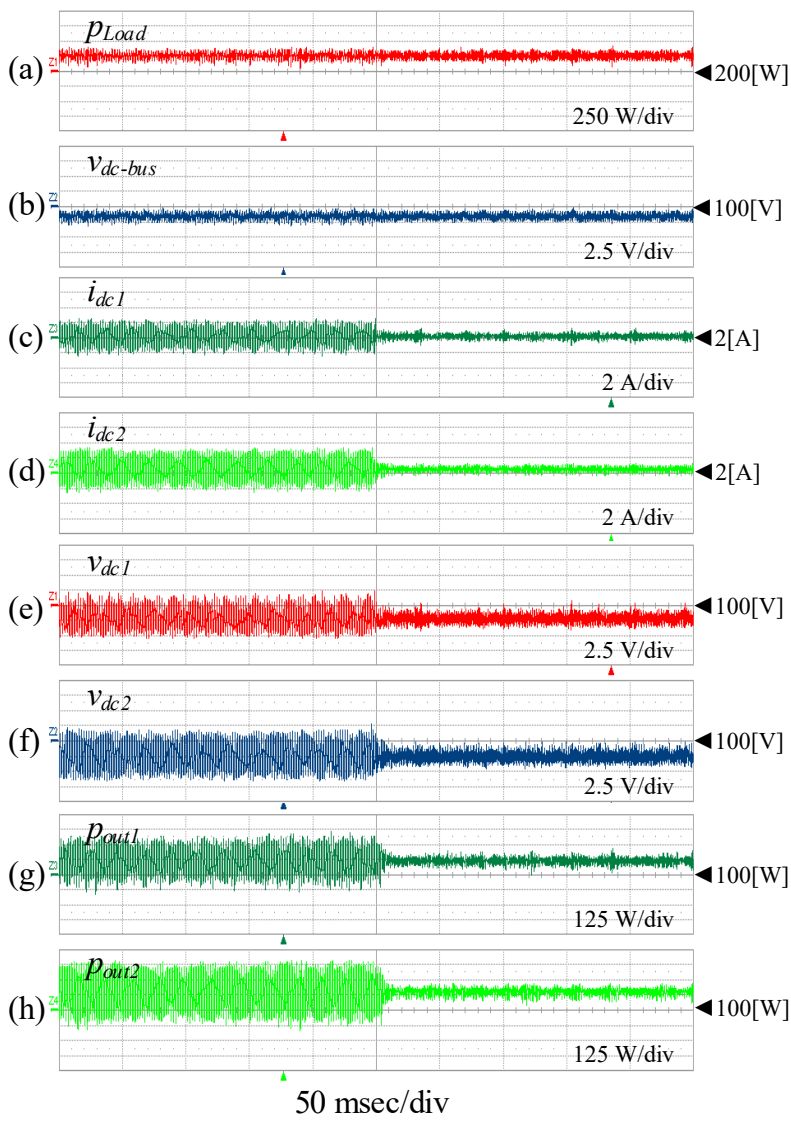

Fig. 21. Operating performance of DC microgrid without/with proposed damping control method.
(a) Load power $\left(p_{\text {Load }}\right)$,
(e) Output voltage \#1 $\left(v_{d c l}\right)$,
(b) DC-bus voltage $\left(v_{d c} b u s\right)$,
(f) Output voltage \#2 $\left(v_{d c 2}\right)$,
(c) Output current \#1 $\left(\overline{i_{d c l}}\right)$,
(g) Output power \#1 ( $\left.p_{\text {out }}\right)$,
(d) Output current $\# 2\left(i_{d c 2}\right)$,
(h) Output power \#2 ( $\left.p_{\text {out } 2}\right)$.

\section{EXPERIMENTAL RESULTS}

Experiments have been carried out to investigate the damping performance of the proposed control scheme. The hardware setup of a small-scaled $100 \mathrm{~V}$ DC power system has been built as shown in Fig. 19, which is comprised of a threephase diode rectifier, two boost converters, a buck-converter load, and a resistive load. The system parameters are listed in Table II. The execution time of the proposed damping control algorithm in DSP is $34 \mu \mathrm{s}$. The experimental test has been performed under unstable condition due to incorrect setting of $f_{d}=200 \mathrm{~Hz}$. Note that the passivity is satisfied when the $f_{d}$ is set lower than $130 \mathrm{~Hz}$ without the proposed damping controller. The load power is changed by adjusting the magnitude of output voltage of the buck converter where the $R_{C P L}$ is constant.

Fig. 20 shows the responses of the DC microgrid without the proposed active damping control when the load power is changed from $200 \mathrm{~W}$ to $450 \mathrm{~W}$ and back to $200 \mathrm{~W}$, where the $f_{d}$ is set as $200 \mathrm{~Hz}$. As it can be seen in Fig. 20(a) and (b), the oscillatory components in load power and DC bus voltage are not increased much at load power of $250 \mathrm{~W}$. However, at 450 $\mathrm{W}$, the oscillatory components in the output currents, voltages

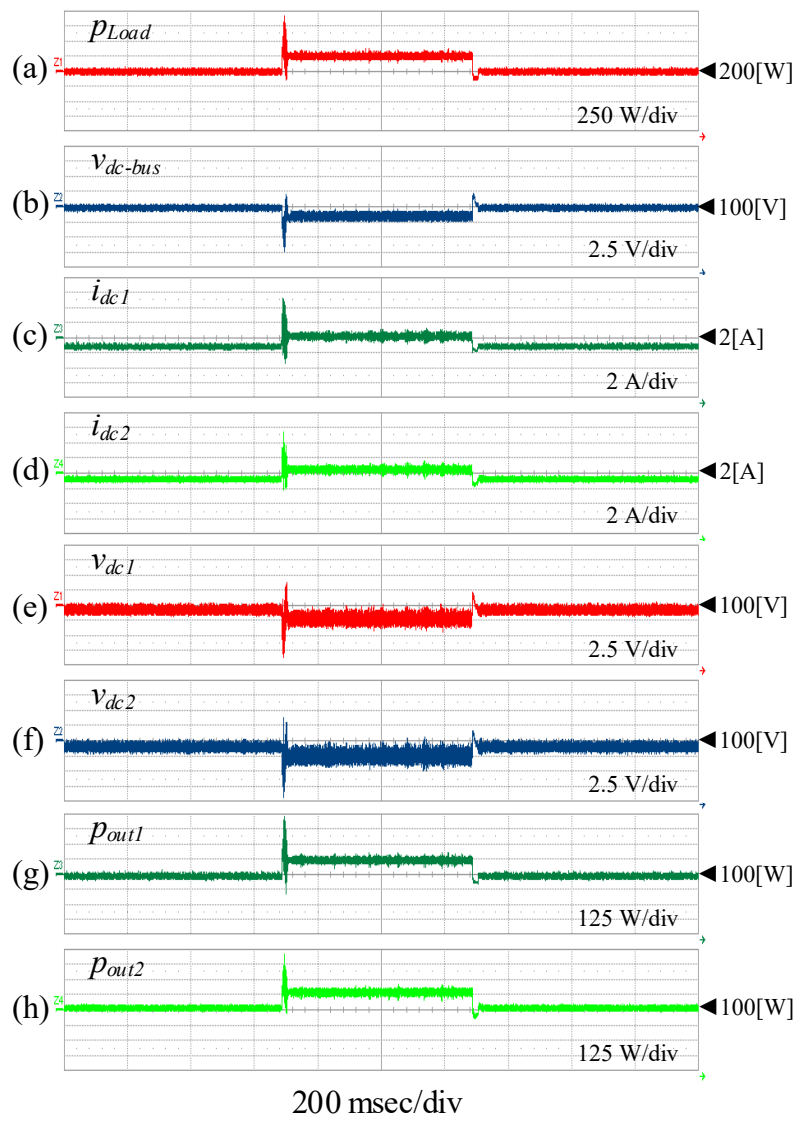

Fig. 22. Responses of DC microgrid with proposed damping control at load changes.
(a) Load power $\left(p_{\text {Load }}\right)$,
(b) DC-bus voltage $\left(v_{d c-b u s}\right)$,
(c) Output current $\# 1\left(i_{d c l}\right)$,
(e) Output voltage \#1 $\left(v_{d c l}\right)$,
(f) Output voltage \#2 $\left(v_{d c 2}\right)$,
(g) Output power \#1 ( $\left.p_{\text {out }}\right)$,
(d) Output current \#2 $\left(i_{d c 2}\right)$,
(h) Output power \#2 ( $\left.p_{\text {out } 2}\right)$.

and powers of the DC-VSCs are increased remarkably since the passivity condition of the bus impedance is not satisfied.

Fig. 21 shows the operating performance of the DC microgrid without/with the proposed control method. Initially, the damping control is not applied, so high oscillating components appear. After the damping control is activated, the oscillatory components are significantly suppressed. Furthermore, the power sharing between two DC VSCs ( $p_{\text {out }}$ and $\left.p_{\text {out } 2}\right)$ is achieved satisfactorily as shown in Fig. 21(g) and (h).

Fig. 22 illustrates the responses of the DC microgrid with the proposed damping control method. On the whole, the oscillatory components are reduced remarkably, compared with those shown in Fig. 20. It is seen that the transient responses in experimental test are faster than HILS results, since $f_{d}$ in the experimental test is $130 \mathrm{~Hz}$ which is higher than that of in HILS, $40 \mathrm{~Hz}$. The value of $f_{d}$ is selected depending on the passivity condition of the bus impedance which should be satisfied as discussed in subsection III-C. 


\section{CONCLUSIONS}

In this paper, a novel active damping control scheme based on the IDA-PBC has been proposed and implemented to attenuate the power and current oscillatory components of V/I droop-controlled DC microgrids. At first, the model of the DC microgrid with the DC VSC, CPL and resistive load has been built. Next, the effects of the system parameters on the passivity-based stability have been analyzed. After that, using the IDA-PBC theory, the damping controller has been designed where asymptotic stability is guaranteed. Besides, a gain selection technique has been developed to complete the controller design. The validity of the proposed control method has been verified by the HILS results in the four cases of the parameter change: the cut-off frequency of the LPF for droop control, the BW of the DC-voltage control loop, the output capacitance of the DC VSC, and the DC-bus capacitance. Furthermore, experimental tests have been performed for a small-scaled hardware system. It has been shown that the proposed method can effectively attenuate the oscillatory components of the power/current in the DC microgrids.

\section{REFERENCES}

[1] T. Dragicevic, P. Wheeler, and F. Blaabjerg, Eds., DC distribution systems and microgrids. Institution of Engineering and Technology, 2018.

[2] T. Dragičević, X. Lu, J. C. Vasquez, and J. M. Guerrero, "DC microgrids-part II: A review of power architectures, applications, and standardization issues," IEEE Trans. Power Electron., vol. 31, no. 5, pp.3528-5349, May. 2016.

[3] T. H. Nguyen, K. Al Hosani, M. El Moursi, F. Blaabjerg, "An overview of modular multilevel converters in HVDC transmission systems with STATCOM operation during pole-to-pole DC short circuits", IEEE Trans. Power Electron., vol. 34, no. 5, pp. 4137-4160, May 2019.

[4] T. Ahmadi, M. Hamzeh, and E. Rokrok, "Hierarchical control scheme for three-port multidirectional DC-DC converters in bipolar DC microgrids," J. Power Electron. vol. 18, no. 5, pp. 1595-1607, Sept. 2018.

[5] D. Kumar, F. Zare, and A. Ghosh, "DC microgrid technology: System architectures $\mathrm{AC}$ grid interfaces grounding schemes power quality communication networks applications and standardizations aspects", IEEE Access, vol. 5, pp. 12230-12256, 2017.

[6] F. Gao and S. Bozhko, "Modeling and impedance analysis of a single DC bus-based multiple-source multiple-load electrical power system," IEEE Trans. Transp. Electrif., vol. 2, no. 3, pp. 335-346, Sept. 2016.

[7] L. Guo, S. Zhang, X. Li, Y. W. Li, C. Wang, and Y. Feng, "Stability analysis and damping enhancement based on frequency-dependent virtual impedance for DC microgrids," IEEE J. Emerg. Sel. Topics Power Electron., vol. 5, no. 1, pp. 338-350, Mar. 2017.

[8] J. Siegers, S. Arrua, and E. Santi, "Allowable bus impedance region for MVDC distribution systems and stabilizing controller design using positive feed-forward control," in Proc. ECCE 2016 - IEEE Energy Convers. Congr. Expo. 2016, pp. 1-8.

[9] M. Hamzeh, M. Ghafouri, H. Karimi, K. Sheshyekani, and J. M. Guerrero, "Power oscillations damping in DC microgrids," IEEE Trans. Energy Convers., vol. 31, no. 3, pp. 970-980, Sept. 2016.

[10] X. Li, L. Guo, C. Wang, S. Zhang, Y. Rong, Y. Feng, and Y. Li, "Robust and autonomous DC bus voltage control and stability analysis for a DC microgrid," in proc. International Power Electronics and Motion Control Conference (ECCE Asia), 2016, pp.1-7.

[11] X. Li, L. Guo, S. Zhang, C. Wang, Y. W. Li, A. Chen, and Y. Feng, "Observer-based DC voltage droop and current feed-forward control of a DC microgrid," IEEE Trans. Smart Grid, vol. 9, no. 5, pp. 5207-5216, Sept. 2018.

[12] N. Rashidirad, M. Hamzeh, K. Sheshyekani, and E. Afjei, "An effective method for low-frequency oscillations damping in multibus DC microgrids," IEEE J. Emerg. Sel. Top. Circuits Syst., vol. 7, no. 3, pp. 403-412, Sept. 2017.

[13] J.-J. E. Slotine, W. Li, Applied Nonlinear Control, NJ, Englewood Cliffs:Prentice-Hall, pp. 53-55, 1991.
[14] Y. Gu, W. Li, and X. He, "Passivity-based control of dc microgrid for self-disciplined stabilization", IEEE Trans. Power Syst., vol. 30, no. 5, pp. 2613-2632, Sep. 2015.

[15] G. Alarcon, V. Cardenas, S. Ramirez, N. Visairo, C. Nufiez, M. Oliver, and H.S.Ramirez, "Non-linear passive control with inductor current feedback for an UPS inverter", in proc. IEEE/PESC, 2000, pp.1414-1418.

[16] M. Mehrasa, M. E. Adabi, E. Pouresmaeil, and J. Adabi, "Passivitybased control technique for integration of DG resources into the power grid", Int. J. Elect. Power Energy Syst., vol. 58, pp. 281-290, Jun. 2014.

[17] K. Fujimoto, S. Sakai, and T. Sugie, "Passivity based control of a class of Hamiltonian systems with nonholonomic constraints," Automatica, vol. 48, no. 12, pp. 3054-3063, Dec. 2012.

[18] M. Zhang, R. Ortega, D. Jeltsema, and H. Su, "Interconnection and damping assignment passivity-based control of port-controlled Hamiltonian systems," Automatica, vol. 38, no.4, pp. 585-596, Apr. 2002.

[19] A. Kwasinski, P. T. Krein, "Stabilization of constant-power loads in dcdc converters using passivity-based control", in Proc. INTELEC, 2007, pp. 867-874.

[20] M. Cupelli, S. K. Bhanderi, S. K. Gurumurthy, and A. Monti, "Voltage control for buck converter based MVDC microgrids with interconnection and damping assignment passivity based control", in Proc. 19th IEEE Mediterranean Electrotech. Conf., 2018, pp. 14-19.

[21] J. Zeng, Z. Zhe, and W. Qiao, "An interconnection and damping assignment passivity-based controller for a dc-dc boost converter with a constant power load", IEEE Trans. Ind. Appl., vol. 50, no. 4, pp. 23142322, Jul./Aug. 2014.

[22] R. V. Meshram, M. Bhagwat, S. Khade, S. R. Wagh, A. M. Stanković, and N. M. Singh, "Port-controlled phasor Hamiltonian modeling and IDA-PBC control of solid-state transformer", IEEE Trans. Control Syst. Technol., vol. 27, no. 1, pp. 161-174, Jan. 2019.

[23] M. Cupelli, S. K. Gurumurthy, S. K. Bhanderi, Z. Yang, P. Joebges, A. Monti, and R. W. De Doncker, "Port controlled Hamiltonian modeling and IDA-PBC control of dual active bridge converters for DC microgrids", IEEE Trans. Ind. Electron., vol. 66, no. 11, pp. 9065-9075, Nov. 2019.

[24] Y.-C. Jeung, D. D. Le, and D.-C. Lee, "Analysis and design of DC-bus voltage controller of energy storage systems in DC Microgrids," IEEE Access, vol. 7, pp. 126696-126708, 2019.

[25] Y.-C. Jeung, "Passivity-based control of distributed generation and energy stirage systems for voltage stabilization in DC microgrids," Ph.D. Dissertation, Yeungnam University, Republic of Korea, 2019.

[26] S. K. Sul, Control of Electric Machine Drive Systems. Hoboken, NJ:Wiley-IEEE Press, 2011.

[27] M. Rodríguez, G. Stahl, L. Corradini, and D. Maksimović, "Smart DC power management system based on software-configurable power modules," IEEE Trans. Power Electron., vol. 28, no. 4, pp. 1571 - 1586, Apr. 2013.

[28] E. K. K. Sng, S. S. Choi, and D. M. Vilathgamuwa, "Analysis of series compensation and DC-link voltage controls of a transformerless selfcharging dynamic voltage restorer," IEEE Trans. Power Deliv., vol. 19, no. 3, pp. 1511 - 1518, Jul. 2004.

[29] Y. Gu, W. Li, and X. He, "Frequency-coordinating virtual impedance for autonomous power management of DC microgrid," IEEE Trans. Power Electron., vol. 30, no. 4, pp. 2328-2337, Apr. 2015.

[30] J. Wang and D. Howe, "A power shaping stabilizing control strategy for dc power systems with constant power loads," IEEE Trans. Power Electron., vol. 23, no. 6, pp. 2982-2989, Nov. 2008.

[31] S. Singh, A. R. Gautam, and D. Fulwani, "Constant power loads and their effects in DC distributed power systems: A review", Renew. Sustain. Energy Rev., vol. 72, pp. 407-421, 2017.

[32] F. Zhao, N. Li, Z. Yin, and X. Tang, "Small-signal modeling and stability analysis of DC microgrid with multiple type of loads", in Proc. IEEE Power Syst. Technol. Conf., pp. 3309-3315, Oct. 2014.

[33] A. Riccobono and E. Santi, "Comprehensive review of stability criteria for DC power distribution systems," IEEE Trans. Ind. Appl., vol. 50, no. 5, pp. 3525-3535, Oct. 2014.

[34] A. Riccobono and E. Santi, "A novel passivity-based stability criterion (PBSC) for switching converter DC distribution systems," in Proc. IEEE Appl. Power Electron. Conf. Expo, 2012, pp. 2560-2567.

[35] L. Guo, S. Zhang, X. Li, Y. W. Li, C. Wang, and Y. Feng, "Stability analysis and damping enhancement based on frequency-dependent virtual impedance for DC microgrids," IEEE J. Emerg. Sel. Top. Power Electron., vol. 5, no. 1, pp. 338-350, Mar. 2017. 
[36] N. Bottrell, M. Prodanovic, and T. C. Green, "Dynamic stability of a microgrid with an active load," IEEE Trans. Power Electron., vol. 28, no. 11, pp. 5107-5119, Nov. 2013.

[37] F. Gao, S. Bozhko, A. Costabeber, G. Asher, and P. Wheeler, "Control design and voltage stability analysis of a droop-controlled electrical power system for more electric aircraft," IEEE Trans. Ind. Electron., vol. 64, no.12, pp. 9271-9281, Dec. 2017.

[38] M. Su, Z. Liu, Y. Sun, H. Han, and X. Hou, "Stability analysis and stabilization methods of DC microgrid with multiple parallel-connected DC-DC converters loaded by CPLs," IEEE Trans. Smart Grid, vol. 9, no.1, pp. 132-142, Jan. 2018.

[39] R. Ortega, A. van der Schaft, B. Maschke, and G. Escobar, "Energyshaping of port-controlled Hamiltonian systems by interconnection," in Proc. IEEE Conf. on Decision and Control (Cat. No.99CH36304), 1999, pp. 1646-1651.

[40] J. Qiu, C. Hu, and S. Yang, "PMSM Hamiltonian energy shaping control with parameters self-tuning PID control," in Proc. Chinese Control Conf. (CCC), 2015, pp. 4506-4511.

[41] "Power electronics development center." [Online]. Available: ni.com/powerdev.

[42] B. Choi, Pulsewidth modulated DC-to-DC power conversion.

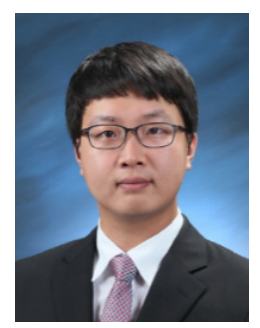

Yoon-Cheul Jeung (S'14-M'20) received the B.S., M.S., and Ph.D. degrees in electrical engineering from Yeungnam University, Gyeongsan, South Korea, in 2010, 2013, and 2019, respectively. He is currently a Senior Researcher at Jeju Global Research Center, Korea Institute and Energy Research. His current research interests include power electronics systems modeling and control, power distribution systems and power management systems.

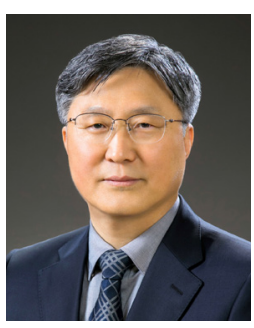

Dong-Choon Lee (S'90-M'95-SM'13) received his B.S., M.S. and Ph.D. degrees in Electrical Engineering from Seoul National University, Seoul, Korea, in 1985, 1987 and 1993, respectively.

He was a Research Engineer for Daewoo Heavy Industry, Korea, from 1987 to 1988 . He has been a faculty member in the Department of Electrical Engineering, Yeungnam University, Gyeongsan, Korea, since 1994. He was a Visiting Scholar in the Power Quality Laboratory, Texas A\&M University, College Station, TX, USA, in 1998; the Electrical Drive Center, University of Nottingham, Nottingham, ENG, UK, in 2001; the Wisconsin Electric Machines and Power Electronics Consortium, University of Wisconsin, Madison, WI, USA, in 2004; and the FREEDM Systems Center, North Carolina State University, Raleigh, NC, USA, from September 2011 to August 2012. He served as the Editor-in-Chief of the Journal of Power Electronics of the Korean Institute of Power Electronics (KIPE), from January 2015 to December 2017. In 2019, he served as the President of KIPE. His current research interests include power converter design and control, renewable energy and its grid connection, AC machine drives, and DC power system.

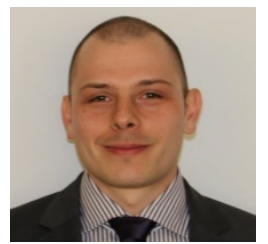

Tomislav Dragičević (S'09-M'13-SM'17) received the M.Sc. and the industrial Ph.D. degrees in Electrical Engineering from the Faculty of Electrical Engineering, University of Zagreb, Croatia, in 2009 and 2013, respectively. From 2013 until 2016 he has been a Postdoctoral researcher at Aalborg University, Denmark. From 2016 until 2020 he was an Associate Professor at Aalborg University, Denmark. From 2020 he is a Professor at the Technical University of Denmark.

He made a guest professor stay at Nottingham University, UK during spring/summer of 2018. His research interest is application of advanced control, optimization and artificial intelligence inspired techniques to provide innovative and effective solutions to emerging challenges in design, control and cyber-security of power electronics intensive electrical distributions systems and microgrids. He has authored and co-authored more than 250 technical publications (more than 120 of them are published in international journals, mostly in IEEE), 8 book chapters and a book in the field.

$\mathrm{He}$ serves as an Associate Editor in the IEEE TRANSACTIONS ON INDUSTRIAL ELECTRONICS, in IEEE TRANSACTIONS ON POWER ELECTRONICS, in IEEE Emerging and Selected Topics in Power Electronics and in IEEE Industrial Electronics Magazine. Dr. Dragičević is a recipient of the Končar prize for the best industrial PhD thesis in Croatia, a Robert Mayer Energy Conservation award, and he is a winner of an Alexander von Humboldt fellowship for experienced researchers.

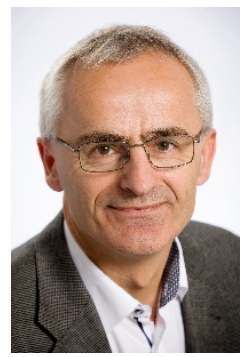

Frede Blaabjerg (S'86-M'88-SM'97-F'03) was with ABB-Scandia, Randers, Denmark, from 1987 to 1988. From 1988 to 1992, he got the PhD degree in Electrical Engineering at Aalborg University in 1995. He became an Assistant Professor in 1992, an Associate Professor in 1996, and a Full Professor of power electronics and drives in 1998. From 2017 he became a Villum Investigator. $\mathrm{He}$ is honoris causa at University Politehnica Timisoara (UPT), Romania and Tallinn Technical University (TTU) in Estonia.

His current research interests include power electronics and its applications such as in wind turbines, PV systems, reliability, harmonics and adjustable speed drives. He has published more than 600 journal papers in the fields of power electronics and its applications. He is the co-author of four monographs and editor of ten books in power electronics and its applications.

He has received 32 IEEE Prize Paper Awards, the IEEE PELS Distinguished Service Award in 2009, the EPE-PEMC Council Award in 2010, the IEEE William E. Newell Power Electronics Award 2014, the Villum Kann Rasmussen Research Award 2014, the Global Energy Prize in 2019 and the 2020 IEEE Edison Medal. He was the Editor-in-Chief of the IEEE TRANSACTIONS ON POWER ELECTRONICS from 2006 to 2012. He has been Distinguished Lecturer for the IEEE Power Electronics Society from 2005 to 2007 and for the IEEE Industry Applications Society from 2010 to 2011 as well as 2017 to 2018. In 2019-2020 he serves a President of IEEE Power Electronics Society. He is Vice-President of the Danish Academy of Technical Sciences too. He is nominated in 2014-2019 by Thomson Reuters to be between the most 250 cited researchers in Engineering in the world. 